\title{
Hot-Melt Extrusion: from Theory to Application in Pharmaceutical Formulation
}

\author{
Hemlata Patil, ${ }^{1}$ Roshan V. Tiwari, ${ }^{1}$ and Michael A. Repka ${ }^{1,2,3}$
}

Received 14 May 2015; accepted 19 June 2015; published online 10 July 2015

\begin{abstract}
Hot-melt extrusion (HME) is a promising technology for the production of new chemical entities in the developmental pipeline and for improving products already on the market. In drug discovery and development, industry estimates that more than $50 \%$ of active pharmaceutical ingredients currently used belong to the biopharmaceutical classification system II (BCS class II), which are characterized as poorly water-soluble compounds and result in formulations with low bioavailability. Therefore, there is a critical need for the pharmaceutical industry to develop formulations that will enhance the solubility and ultimately the bioavailability of these compounds. HME technology also offers an opportunity to earn intellectual property, which is evident from an increasing number of patents and publications that have included it as a novel pharmaceutical formulation technology over the past decades. This review had a threefold objective. First, it sought to provide an overview of HME principles and present detailed engineered extrusion equipment designs. Second, it included a number of published reports on the application of HME techniques that covered the fields of solid dispersions, microencapsulation, taste masking, targeted drug delivery systems, sustained release, films, nanotechnology, floating drug delivery systems, implants, and continuous manufacturing using the wet granulation process. Lastly, this review discussed the importance of using the quality by design approach in drug development, evaluated the process analytical technology used in pharmaceutical HME monitoring and control, discussed techniques used in HME, and emphasized the potential for monitoring and controlling hot-melt technology.
\end{abstract}

KEY WORDS: hot-melt extrusion; process analytical technology; quality by design; screw design; solid dispersion.

\section{INTRODUCTION}

Hot-melt extrusion (HME) processing was established in the early 1930s, and during that time, it rapidly became the most widely applied processing technology in the plastic, rubber, and food industries. The application of HME expanded to the pharmaceutical industry at the beginning of the 1970s and was used in formulation and product development as well as manufacturing. The first application of HME as a manufacturing tool in the pharmaceutical industry was investigated by ElEgakey et al. (1) using poly (vinyl acetate-co-methacrylic acid) and epoxy resin containing a secondary amine as a polymeric carrier (1). HME is a continuous pharmaceutical process that involves pumping polymeric materials with a rotating screw at temperatures above their glass transition temperature $\left(T_{\mathrm{g}}\right)$ and sometimes above the melting temperature $\left(T_{\mathrm{m}}\right)$ to

\footnotetext{
${ }^{1}$ Department of Pharmaceutics and Drug Delivery, School of Pharmacy, The University of Mississippi, University, Mississippi 38677, USA.

${ }^{2}$ Pii Center for Pharmaceutical Technology, School of Pharmacy, The University of Mississippi, Oxford, Mississippi 38677, USA.

${ }^{3}$ To whom correspondence should be addressed. (e-mail: marepka@olemiss.edu)
}

achieve molecular level mixing of the active compounds and thermoplastic binders, polymers, or both $(2,3)$. This molecular mixing converts the components into an amorphous product with a uniform shape and density, thereby increasing the dissolution profile of the poorly water-soluble drug. Additionally, HME has been utilized for the delivery of water-soluble drugs with several applications such as taste masking $(2,3)$. This exciting yet challenging technology may offer several advantages over conventional pharmaceutical manufacturing processes such as shorter and more efficient time to achieve the final product, environmental advantages due to the elimination of solvent use, and increased efficiency of drug delivery to the patient. As a result, HME has emerged as an alternative platform technology to other traditional techniques for manufacturing pharmaceutical dosage forms such as tablets, capsules, films, and implants for drug delivery via oral, transdermal, and transmucosal routes. The introduction of HME to pharmaceutical formulation development has made sophisticated equipment such as the extruder, customized downstream auxiliary equipment, and monitoring tools available for application in evaluating the performance and product quality. This enhanced availability has supported the growth of this innovative technique in pharmaceutical manufacturing processes utilizing both single and twin-screw extruders. 
To date, several research articles have been published describing the use of HME as the novel technique of choice in dealing with the day-to-day formulation challenges of new active pharmaceutical ingredients (APIs). Moreover, numerous aspects of the HME technology have been extensively cited in the literature. Additionally, the number of patents based on HME techniques has risen steadily worldwide in recent decades (4-12).

Regulatory bodies continue to encourage the investment in the use of quality by design (QbD) and process analytical technology (PAT), which are already essential tools in the HME process, to enhance product and process understanding. As a continuous process, HME fits perfectly within this framework. PAT tools including Raman and near-infrared (NIR) spectroscopy play an important role in real-time quality evaluation and understanding of the extrusion process in the production pharmaceutical dosage forms.

\section{HOT-MELT EXTRUSION: EQUIPMENT AND PROCESS}

Extrusion is the process of changing the physical properties of the substance by forcing it through an orifice or die under controlled conditions. The extrusion equipment is classified into three main categories: ram, radial screen, and roll and screw extruders (13). Among these, the screw extruders are the most important in the pharmaceutical industry because they continuously convert feed material to the finished form such as a rod, tube, or film. The rotating screws force the feed material forward towards the die, and the material is softened by the frictional heat developed through the barrel wall. The feed reaches the end of the screw in a viscous state that can then be forced through an orifice (or die) and molded into the desired shape (14).

\section{Types of Screw Extruders}

Pharmaceutical screw extruders are designed based on the desired extrudate and are required to meet the current regulatory standards for the manufacture of dosage forms. They are classified as follows:

1. Single-screw extruders (SSEs): smooth or grooved barrel.

2. Twin-screw extruders (TSEs): co-rotating or counterrotating with intermeshing or non-intermeshing screws.

3. Multi-screw extruders (MSEs): static or rotating central shaft.

Irrespective of type, function, or process complexity, the different extruders must be capable of rotating the screw at a given operational speed while compensating for the torque and generated shear rate from both the material being extruded and the type of screw in use. The extrusion assembly consists of a motor, which acts as a drive unit; an extrusion barrel, which is often manufactured in sections and is bolted or clamped together; and a rotating screw and an end-plate die connected to the end of the barrel. This configuration ultimately determines the shape of the extruded product regardless of the size and shape of the screw inside the stationary cylindrical barrel $(4,15)$. The extruder process materials are bound by screw flights and a barrel wall. A central electronic control unit is connected to the extrusion unit in order to control the process parameters such as screw speed (rpm), feed rate, temperatures along the barrel and the die, and the vacuum level for devolatilization. Typical electronic control panel readouts include the melt pressure and temperature, motor amperage, viscosity, and specific energy consumption. A schematic of a typical extruder assembly is illustrated in Fig. 1 (16).

\section{SSE}

SSEs are the most widely used extruders because they are mechanically simple devices that have only had slight modifications to their operational principles since their invention around 1897 (17). The SSE consists of one continuously rotating screw in a barrel that results in good quality molten material (melt) and generates a high stable pressure for a consistent output (Fig. 2). In general, the screw design may consist of 20 or more turns with a pitch similar to the screw diameter, thereby creating a long slender machine in which substantial longitudinal temperature gradients can be maintained and controlled. It also provides considerable residence time, thereby permitting an adequate degree of end-to-end mixing (18). Different operations can be performed in the SSE such as feeding of raw materials, conveying, melting, devolatilizing, pumping, and shaping. Mixing can also accomplished for less demanding applications. The SSE receives the raw material in the feeding area and then conveys it along a flighted screw enclosed in the barrel. The SSE is flood fed via the feed hopper, and the screw rpm determines the output rate. However, they may occasionally be starve fed, where the feed system sets the mass flow rate and is independent of the screw rpm. The flights of the screw and the inner surface of the barrel form a flow channel due to the rotation of the screw. As a function of the frictional forces in the flow channel, the SSE propels the raw material towards the proximal portion of the screw. The heated barrel surface and the mechanical energy input supplied by the screws induce the material to form a melt pool, which is inversely proportional to the solid bed size, and therefore, the melt pool increases as the solid bed decreases. Finally, the molten extrudate is pumped through a die that imparts a definite shape for further downstream processing. These essential features combined with low maintenance and low cost make the HME the equipment of choice for the production of almost all extruded products $(6,19)$.

2. TSE

The first TSE was introduced in the late 1930s in Italy, with the aim of combining the mechanical actions of several available devices into a single unit. The TSE, as the name indicates, has two agitator assemblies mounted on parallel shafts (Fig. 2). The use of two screws permits different types of configurations and also imposes different conditions in all the zones of the extruder, from the feeding of the material via the hopper to the rotating screw and finally to conveying the material to the metered pumping zone $(6,20)$. Therefore, 


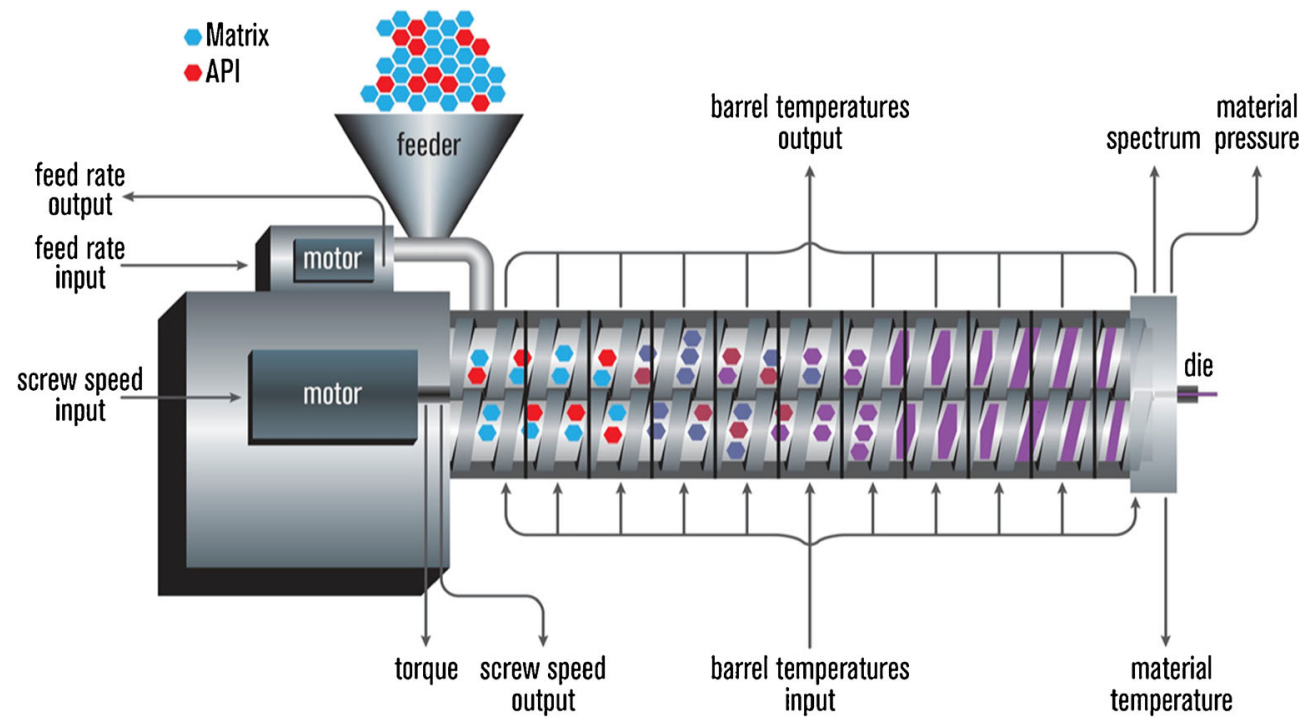

Fig. 1. Schematic of typical extruder system. API active pharmaceutical ingredient

different types of TSEs are available, which each have distinct operating mechanisms and processing applications. The screws in the TSEs can either be co-rotating (same direction) or be counter-rotating (opposite direction). The two types of TSEs can be further classified as fully intermeshing or nonintermeshing (Fig. 3). The fully intermeshing TSE is the most popular because the design incorporates a self-cleaning feature and, thereby, not only reduces the non-motion but also prevents the localized overheating of the raw materials with the extruder. Therefore, the raw material does not rotate along the screw or adhere to the "first in/first out" principle of the extruder. In comparison to the fully intermeshing TSE, the non-intermeshing is less popular in the mixing application due to its weaker screw interactions and lower self-cleaning capability. These types of screws are often used to process highly viscous materials and for the removal of large amounts of volatile substances. The non-intermeshing TSEs are not susceptible to high torque generation while processing highly viscous materials because these screws are positioned separately from each other $(6,20,21)$. The TSE is

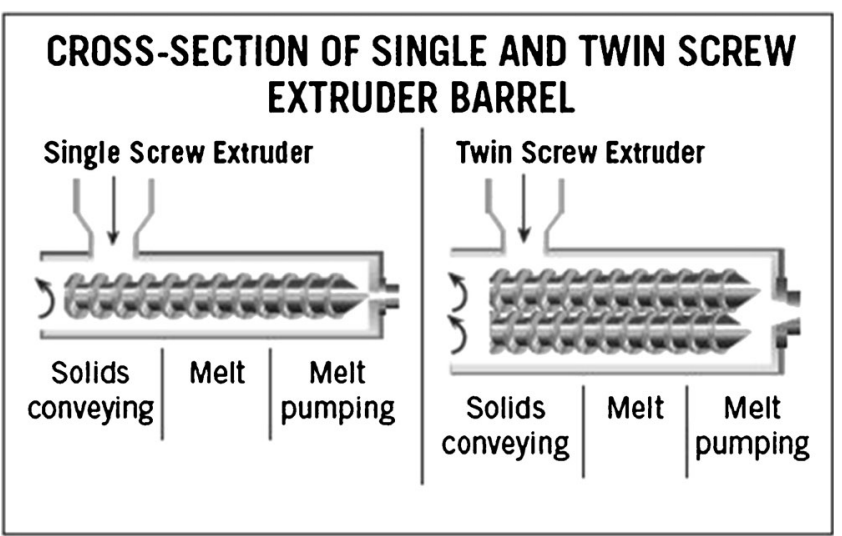

Fig. 2. Cross-section of single- and twin-screw extruders (17) characterized by the following descriptive features $(4,6)$ :

(a) Reduced residence time: The residence time of a typical extrusion process ranges from 5 to $10 \mathrm{~min}$ based on the screw speed and feed rate.

(b) Self-cleaning screw feature: The flight of one of the intermeshing screws cleans the root of the adjacent screw and, thereby, ensures the complete emptying of the equipment and reduces the product waste at the end of the production batch.

(c) Minimum supply: Combining the continuous operation of the equipment with continuous feeding of the material reduces the work supply of the formulation batch.

(d) Flexibility: The operating parameters can be altered easily and continuously to change the extrusion rate or mixing function. The segmented screw elements permit the easy optimization of the agitator designs to work within the process application. The die plates can also be easily exchanged to alter the extrudate diameter, which enables the processing of a wide variety of formulations on a single machine.

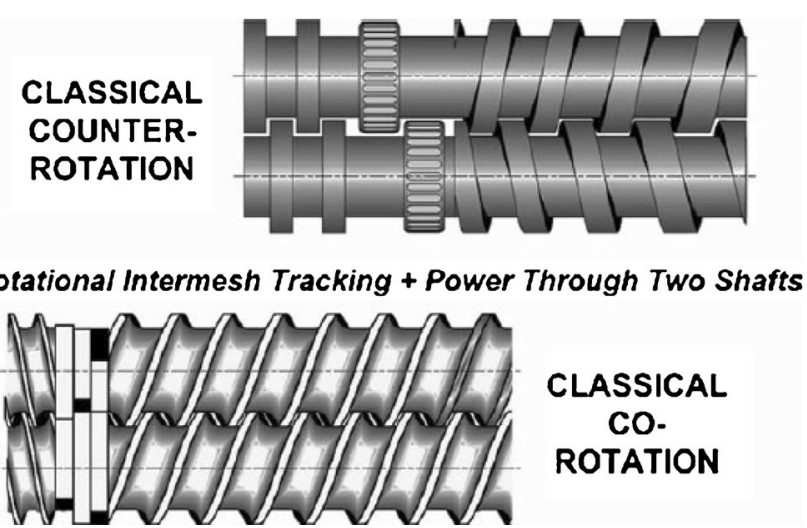

Fig. 3. Classical intermeshing co-rotating and counter-rotating screws (20) 
(e) Enhanced mixing: The screws are designed in such a way that it provides two types of mixing. First, in distributive mixing, the materials are evenly blended with minimal degradation, and therefore, it is mainly used for heat- and shearsensitive APIs. The second type called dispersive mixing involves breaking down the droplet or solid domain to fine morphologies using energy at or slightly higher than the threshold level needed. This mixing facilitates the efficient compounding of two or more APIs in the twinscrew extruder. A list of some commercially available extruders is provided in Table I.

3. MSE

The extruders that incorporate more than two screws are generally referred to as MSE. Depending upon the number of screws used in the extruder, the assembly may vary. For example, if the extruder has six or eight screws, then they are organized in a circumferential manner. On the other hand, if the extruder has three or five screws, then they are set up in a linear fashion, and in the case of the four screws, the extruder has a control screw and three spurs (22). These arrangements of the screws in the MSE are in no unique sense and may vary depending upon the requirements of the food and pharmaceutical industries. MSE are preferred over SSE as a highly shear-dominated flow of the melted material in SSE results in a large amount of heat generation, which thermally degrades the material (thermal labile material). However, in MSE, due to positive displacement flow in the intermeshing region between the screws, prevention of degradation of thermal labile materials is attained (23).

\section{Differences Between SSE and TSE}

The TSE has become more popular in industrial applications because it offers several advantages over the SSE such as easier material feeding, higher kneading and dispersing capacity, lower tendency to overheat, higher process productivity and flexibility, and better control of process parameters. However, the SSE does have the advantage of mechanical simplicity as well as lower maintenance and cost over the TSE $(6,24)$. The basic difference between the SSE and TSE is in their modes of operation. In the SSE, the friction between the materials, the rotating screw, and the barrel allows the material to rotate and push forward, which generates heat. Therefore, increasing the screw speed increases the frictional heat and elevates the temperature, which may degrade heatsensitive drugs. Although the SSE forms a good quality melt, during the melting process, it generates high pressure, which compresses the dispersed particulates leading to agglomeration and poor mixing due to insufficient shear deformation. In contrast, the TSE heating is controlled from outside sources as the intermeshing screws push the material forward with the relative motion of the flight of one screw inside the channel on the other. Therefore, in the TSE, heat generation is independent of the screw speed. In addition, the twin screws can orient in varying configurations depending on the desired level of shear and the speed of mixing/operation. This difference in the operation becomes particularly important when processing thermolabile drugs (20). Compared to the SSE, the intermeshing co-rotating of the TSE provides better mixing, producing a more homogeneous solid containing finely distributed and dispersed active compounds, higher kneading potential, and better melt temperature control (5). Therefore, there is a lower overheating

Table I. List of Some Commercially Available Pharmaceutical-Grade Extruders (10)

\begin{tabular}{|c|c|c|c|c|}
\hline Company & Extruder & $\begin{array}{r}\text { Capacity } \\
(\mathrm{kg} / \mathrm{h})\end{array}$ & $\begin{array}{l}\text { Screw diameter } \\
\quad(\mathrm{mm})\end{array}$ & Screw assembly \\
\hline \multirow[t]{9}{*}{ Thermo Scientific } & Pharma mini-HME micro-compounder & $0.01-0.2$ & Variable & Co- and counter-rotating \\
\hline & 11-mm parallel twin-screw extruder & $0.02-2.5$ & 11 & Co-rotating multiple elements \\
\hline & HAAKE MiniLab II micro-compounder & $0.01-0.2$ & Variable & Conical co- and counter-rotating \\
\hline & EuroLab 16XL & $0.2-10$ & 16 & Parallel co-rotating \\
\hline & HAAKE Rheomex PTW 16 OS & $0.2-10$ & 16 & Parallel co-rotating \\
\hline & HAAKE Rheomex PTW 24 OS & $0.5-50$ & 24 & Parallel co-rotating \\
\hline & HAAKE Rheomex PTW 100 OS & $0.2-5$ & Variable & Conical counter-rotating \\
\hline & Pharma 16 HME & $0.2-5$ & 16 & Parallel co-rotating \\
\hline & TSE $24 \mathrm{MC}$ & $0.2-50$ & 24 & Parallel co-rotating \\
\hline \multirow[t]{5}{*}{ Leistritz } & Nano16 & $0.2-0.8$ & 16 & Co-rotating \\
\hline & ZSE $18 \mathrm{HP}$ PH & $0.5-7$ & 18 & Co-rotating \\
\hline & ZSE 27 HP PH & $2-60$ & 27 & Co-rotating \\
\hline & ZSE $40 \mathrm{HP}$ PH & $20-180$ & 40 & Co-rotating \\
\hline & ZSE $50 \mathrm{HP}$ PH & $60-300$ & 50 & Co-rotating \\
\hline \multirow[t]{3}{*}{ Gabler } & DE 40 & $5-100$ & 40 & Co-rotating \\
\hline & DE 100 & $80-800$ & 100 & Co-rotating \\
\hline & DE 120 & $80-800$ & 120 & Co-rotating \\
\hline \multirow[t]{2}{*}{ Coperion Brabender } & ZSK 18-70 Twin-screw stand-alone & - & $18-70$ & Co-rotating \\
\hline & TSE 20/40 & - & 20 & Co-rotating \\
\hline
\end{tabular}


tendency, which is important for sensitive APIs, lower dependence on the materials friction coefficients, and shorter residence time due to relatively fast melting than there is with the SSE (5).

In an extrusion process, the dimensions of the screws, which are given in terms of the length-to-diameter ratio $(L /$ $D)$, positioned inside the stationary cylindrical barrel is an important characteristic to consider regardless of whether the extrusion equipment is an SSE or TSE. For example, an extruder that is $1000-\mathrm{mm}$ long with a $25-\mathrm{mm}$ screw diameter has a 40:1 $L / D$. Typical extrusion process $L / D$ s are in the 20 40:1 range or higher. Typically, the SSE has a 36:1 or shorter $L / D$. The length assigned for each process operation depends upon extruder barrel $L / D$. For instance, an SSE with a 24:1 L/ $D$ might have four equal $L / D$ s assigned to raw material conveying, melting, mixing, and pumping, whereas a 30:1 L/D would allow the addition of $6 \mathrm{~L} / \mathrm{D}$ s to a crucial part of the screw where further feeding, pumping, melting, or mixing is required. The length of a typical TSE barrel section is four times the screw diameter. For instance, with 11 sections, the extruder would be 44:1 L/D long. Therefore, the intermeshing TSE may be configured for up to $60: 1 L / D$, whereas the nonintermeshing TSE can be specified at a 100:1 or longer $L / D$ because there are no intermesh clearance constraints. The extruder residence times range between $5 \mathrm{~s}$ and $10 \mathrm{~min}$, depending on the $L / D$, type of extruder, screw design, and the operation format. The size of an extruder is determined based on the diameter of the screw used in the system. For example, in a pharmaceutical pilot scale extruder, the screws range from 18 to $30 \mathrm{~mm}$ while for pharmaceutical production scale processes, the machines are much larger with diameters typically exceeding 50-60 mm. In addition, the screw dimension also varies with a change in the length of the barrel. In advanced extruders, the screws can be separated by clamps or extended in proportion to the length of the barrel itself $(6,13,14,19,21)$.

Most screws are made from surface-coated stainless steel to reduce friction and the possibility of chemical reactions. The flights are ground and fit closely in the barrel, and the general-purpose screw has a flight pitch equal to the screw diameter. The screw is typically divided into three equal sections along the length of the barrel including the feed, the compression, and the metering sections. The raw material is fed from the hopper directly into the feed section, which has flights that are deeper or of a greater pitch (Fig. 4). This configuration enables the raw material to fall easily into the screw for conveyance along the barrel. The pitch and helix angles determine the output of the extruder at a constant screw speed. The material is conveyed as a solid plug to the transition zone where it is mixed, compressed, melted, and plasticized. The feed channel depth is constant and associated with the solid conveyance, and a decrease in the channel depth in the compression zone increases the pressure, which removes any entrapped air. The polymer begins to soften and melt in the compression zone. The melt then moves by circulation in a helical path by a process consisting of transverse flow, drag flow, pressure flow, and leakages; the latter two mechanisms reverse the flow of the material along the barrel. Thermoplastic polymers primarily exist in a molten state when entering the metering section, which has the main function of reducing the pulsating flow to ensure a uniform delivery rate through the die cavity. The mass flow rate of the extrudate is highly dependent upon the channel depth and length of the metering section $(4,6,25)$.

The temperatures of all of the barrels are independent and can be accurately controlled to maintain relatively low $\left(30^{\circ} \mathrm{C}\right)$ to high $\left(250^{\circ} \mathrm{C}\right)$ temperatures $(26)$. The molten mass is heated by external heating, shear forces, or both as it flows through the extruder, and the polymer matrix is thereby plasticized to incorporate the drug material. The matrix can be considered as a highly viscous solvent in cases where the solid melt extrusion dispersions are prepared using the melt extrusion process since no solvent is required and the drug dissolves in the polymeric matrix. Finally, shaping the molten strand as it leaves the extruder die is one of the most important applications of HME in the pharmaceutical industry. Typically, there are two different methods of achieving this.

1. Calendaring: The molten strand is forced between two calendar rollers, producing films, flakes, or sheets. The most common application for this is in the packaging of medical and pharmaceutical products. In addition, it is used for transdermal drug delivery systems where an active ingredient is homogeneously mixed with a carrier and applied to a substrate.

2. Pellet forming: This can be achieved using several pieces of equipment including traveling shears, traveling saws, and a rotary knife to cut spaghetti-like extruded strands. The strands are then pulled through a type of cooling medium using the feed rolls of the pelletizer and cut to the required length. The diameter of the final pellet is controlled by the diameter of the orifice and the speed at which the feed rolls pull the strand. Typically, 3-mm pellets or smaller can be produced. Larger pellets of up to $20 \mathrm{~mm}$ are also possible but uncommon in the pharmaceutical industry (27-29).

In summary, excessive heat stress of the active substance being processed using HME is avoided by the shorter residence time in the extruder (approximately $2 \mathrm{~min}$ ). The shortened residence time is particularly useful in the formulation of thermolabile drug substances. In addition, oxygen and moisture can be almost eliminated, which is an advantage for oxidation- and hydrolysis-sensitive drugs. The benefits and challenges of HME are illustrated in Table II.

The last section of the extrusion assembly is the die, which is attached to the end of the barrel. A properly designed extrusion die is extremely important to achieve the required shape and dimensions of the extruded product. The function of the extrusion die is to shape the melt as it exits the extruder into the desired cross-section, depending on the extrudate being produced. The cross-section of the extrudate will increase on leaving the die, a phenomenon known as "die swell" depending on the viscoelastic properties of the polymers. This entropy-driven event occurs when the individual polymer chains recover from the deformation imposed by the rotating screw by velocity relaxation $(6,30)$. Velocity relaxation is a unification of the melt flow and viscoelastic relaxation of the strained polymer molecules, and the increase in the radius of gyration of the individual polymer chains also contributes to the die swell $(6,30)$. Extrusion dies vary in shape and complexity to meet the requirements of the product being manufactured. Currently, computer-based simulation tools facilitate the designing of different types of extrusion dies. There 


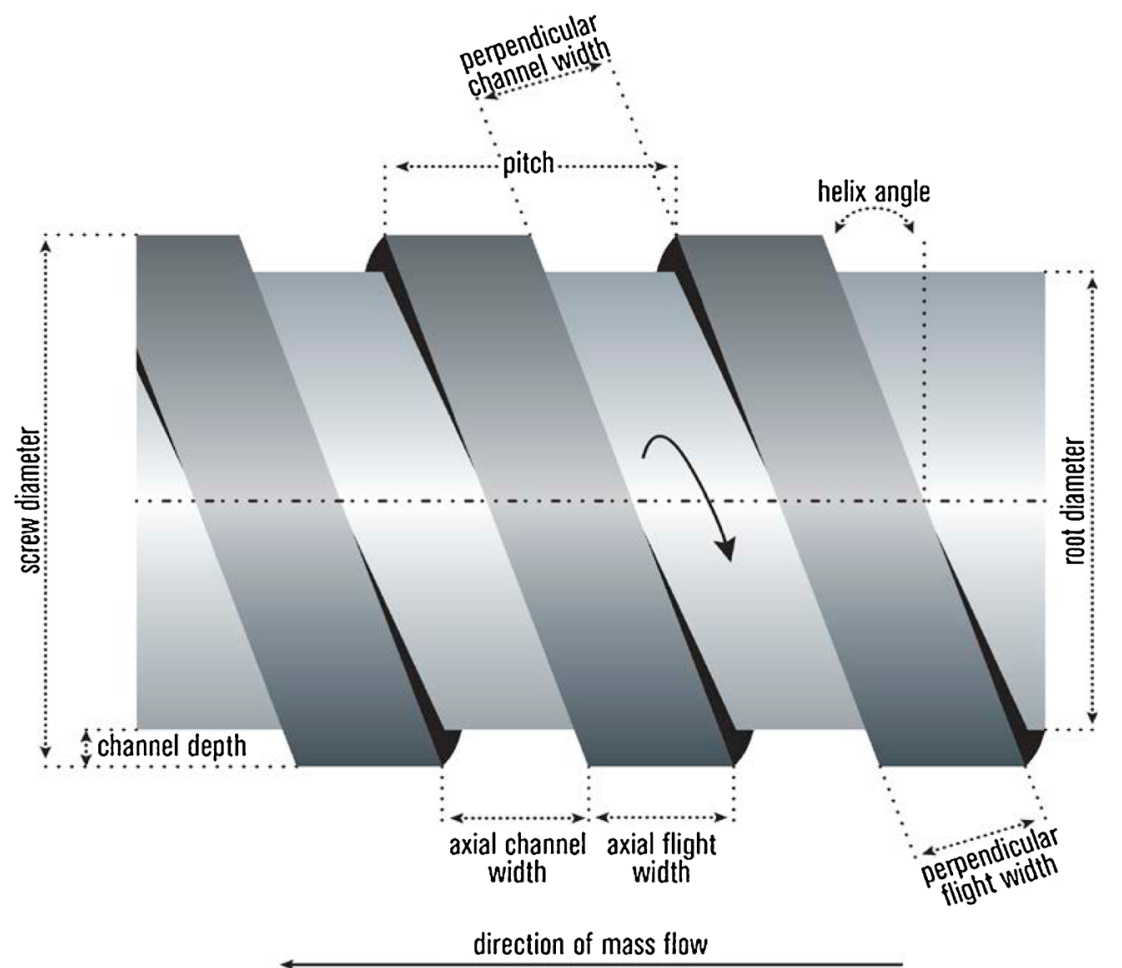

Fig. 4. Extrusion screw geometry

are four different shapes for products made by extrusion dies including the extrudate strands, films, sheets, and granules.

\section{MATERIALS USED IN HME}

The use of HME in pharmaceutical applications requires the inclusion of a number of functional excipients and a complex mixture of active ingredients in the formulation, which should possess the following characteristics $(6,31,32)$ :

1. They must meet the same levels of purity and safety as those used in traditional dosage forms.

2. They must be able to deform easily inside the extruder and solidify on exiting it.

3. They must be thermostable and maintain an acceptable physical and chemical stability during the HME process and afterward during long-term storage. Thermal stability of the individual compounds is a prerequisite for the process, although the short processing time used in the HME process does not limit the use of all thermolabile compounds.

4. The desired in vitro release and in vivo performance should be achieved by the final dosage form.

These functional excipients can be broadly classified as matrix carriers, release-modifying agents, fillers, thermal lubricants, stabilizing agents, plasticizers, antioxidants, and miscellaneous additives. The selection and use of the various excipients can impart specific properties to hot-melt extruded pharmaceuticals in a manner similar to those obtained with traditional dosage forms.

\section{Carriers}

HME can be used as a drug delivery technology where an active compound is embedded in a carrier system, which is usually composed of one or more meltable substances and

Table II. Benefits and Limitations of Hot-Melt Extrusion (HME)

\begin{tabular}{ll}
\hline Benefits & Limitations \\
\hline Continuous process & Processing thermolabile compounds \\
High throughput & Limited number of heat stable polymers \\
Solvent-free technique & Requires raw materials with high flow properties \\
Increases solubility and bioavailability of poorly water-soluble drugs & High energy input \\
No downstream processing required & \\
Wide application in pharmaceutical industry & \\
Useful for low compressibility index active pharmaceutical ingredients (APIs) & \\
Comparatively thermodynamically stable & \\
Exposure to oxygen in extrusion channel is limited &
\end{tabular}


other functional excipients. The meltable substance is usually a polymer or low-melting-point wax. The molten polymers or waxes used in the HME process function as thermal binders, which act as drug depots, drug-release retardants, or both following cooling and solidification. The carriers used in hotmelt extruded dosage forms can be grouped into two categories including polymeric and non-polymeric carriers. The selection of an appropriate carrier for the HME process mainly depends on the drug-polymer miscibility, polymer stability, and function of the final dosage form. Because numerous drugs are heat-sensitive, HME requires the selection of polymers that can be processed at low temperatures. The carriers that have been used include water-insoluble polymers and waxes such as ethyl cellulose or carnauba wax from which the rate of drug release is diffusion controlled. Granules containing diclofenac sodium using carnauba wax have been reported (33). The use of waxes and other wax-based materials has the potential advantage that these materials are relatively inert. Commonly used polymeric carriers include polyvinylpyrrolidone (PVP) (34) or its copolymers such as polyvinylpyrrolidone-vinyl acetate (PVP-VA) (35), poly (ethylene-co-vinyl acetate) (36), various grades of polyethylene glycol (PEG) (37), cellulose-esters (38) and celluloseacrylates (39), polyethylene oxides (PEOs) of varying molecular weights (40), poly-methacrylate derivatives, and poloxamers. Repka et al. (41) showed that a thermolabile drug such as hydrocortisone could be incorporated into hydroxypropylcellulose (HPC) films produced by melt extrusion (41). A US patent 7,795,237 (42) reports the use of PEG/ polypropylene glycol block copolymer in preparing solid suspensions using HME of an isobutyric acid salt, for the treatment of hepatitis C. PEO was studied for use as a drug carrier in HME using various drugs such as chlorpheniramine maleate and nifedipine $(40,43,44)$. Among the different classes of biodegradable polymers, the thermoplastic aliphatic poly (esters) like polylactic acid (PLA), poly(glycolide) (PGA), and poly(lactide-co-glycolide) (PLGA), the copolymer of lactide and glycolide, have been used in HME. Starch and starch derivatives have also been used with low-molecularweight excipients such as sugars, sugar alcohols, and waxes $(6,25)$. The polymers used in HME for different dosage forms are essentially required to be thermoplastic.

\section{API}

The physical and chemical properties of the active ingredient often limit the formulation and preparation choices available for the development of desired dosage forms. In order to improve physical and chemical stability, the majority of drugs currently used are prepared in a crystalline state, which is characterized by a regularly ordered lattice structure. The crystalline form has unique advantages over the amorphous form including physical (e.g., hygroscopicity) and chemical stability, processability, and the availability of a diversity of forms (e.g., polymorphs, anhydrates, hydrates, and solvates). Therefore, crystalline drugs formulated using HME are mostly sustained/ controlled-release preparations. Polymer-based sustained-release matrices (using Eudragit ${ }^{\circledR}$ RL and RS as carriers) were previously processed by Quinten et al. (44) via HME in combination with injection molding incorporating different metoprolol salts (tartrate, succinate, and fumarate) as the API (43). Drug release varies depending on the salt form due to the changes in the matrix hydration and permeability caused by crystal lattices. Although crystalline products are thermodynamically stable, it is still important to know the possible polymorphic changes that the API might undergo during HME processing to ensure product stability. To overcome the limitation of poor dissolution exhibited by crystalline products, the pharmaceutical delivery system may also be prepared in an amorphous form. However, amorphous products are thermodynamically unstable. The process of devitrification very commonly occurs with amorphous products and causes them to convert to the crystalline form, following storage. Therefore, glass transition temperature $\left(T_{\mathrm{g}}\right)$ monitoring is essential for amorphous products. Hancock (45) suggested that the $T_{\mathrm{g}}$ should be at least $50^{\circ} \mathrm{C}$ above the storage temperature to ensure the product remains stable for its shelf life (45).

In addition to exhibiting thermal degradation, the active ingredient may enhance or interfere with the functionality of the other components in the formulation. Oxprenolol hydrochloride was shown to melt under the HME processing conditions, thereby decreasing the viscosity of the extrudate and yielding a material with poor handling properties (46). In a similar study, a formulation (fenoprofen calcium) prepared by injection molding inhibited the hardening of the PEG-MCC matrix, resulting in an unusable product (47). Lidocaine was also shown to lower the $T_{\mathrm{g}}$ of Eudragit ${ }^{\circledR} \mathrm{E} / \mathrm{HDPE}$ films (48) and hydrocortisone time-dependently lowered the $T_{\mathrm{g}}$ of HPC films (41).

\section{Plasticizers}

Plasticizers are low-molecular-weight compounds capable of softening polymers to make them more flexible and lower the processing temperature of the HME, which can reduce the degradation of thermolabile APIs. In addition, plasticizers modify the extrudate properties during the HME or post-die processing and determine the release properties of the final dosage form. Plasticizers can be divided into different classes such as traditional, non-traditional, and special plasticizers. The most commonly used traditional plasticizers are triacetin (48), citrate ester $(41,49)$, vitamin E D-alpha tocopheryl PEG 1000 succinate (TPGS) (50), surfactants (51), and lowmolecular-weight polyethylene glycols (31). Non-traditional plasticizers are included in formulations to serve other critical functions and are often low-molecular-weight materials such as the active substance itself (52-55). Special plasticizers are low-molecular-weight materials, which also act as plasticizers for polymeric carriers depending on their physical state. This category includes pressurized $\mathrm{CO}_{2}$, which when injected during the HME process, reduces the temperature of various polymers in addition to acting as a foaming agent (56-59).

\section{PHARMACEUTICAL APPLICATIONS OF HME}

\section{Solid Dispersions for Solubility/Bioavailability Enhancement}

A solid dispersion is a system in which one or more active ingredients are molecularly distributed into a hydrophilic inert carrier matrix. The formulation of an API into a solid dispersion converts the poorly water-soluble crystalline form to the amorphous, which increases its solubility. Different techniques 
are commonly used to prepare solid dispersions including the melt fusion and solvent evaporation techniques. HME is an extremely suitable technique for the formation of solid dispersions, and its main advantage is the process does not require solvent use. Therefore, the associated solvent-related stability risks that can occur during the shelf life of the formulation are avoided since there is no residual solvent. Based on the configuration of the equipment and processing temperature, the TSE is emerging as the most viable option in the pharmaceutical industry for the production of solid dispersions (60-63). We will now highlight some practical examples from the literature, which present relevant discoveries and advances in the application of HME for the production of solid dispersions.

Hulsmann et al. (64) studied the HME technique as an alternative method to enhance the dissolution rate of the poorly water-soluble drug $17 \beta$-estradiol hemihydrate. Different compositions of excipients such as PEG 6000, PVP, or a vinylpyrrolidone-vinyl acetate copolymer were used as polymers, and Sucroester WE15 and Gelucire 44/14 were additives. The solid dispersions significantly increased the dissolution rate compared to that of the pure drug or the physical mixtures (Fig. 5). A 30-fold increase in the dissolution rate was obtained for the formulation containing $17 \beta$-estradiol, PVP, and Gelucire 44/14 at 10, 50, and 40\%, respectively. The solid dispersion was then tableted, and the dissolution studies showed that the improvement in the dissolution was maintained with the tablet dosage form (64).

Nakamichi et al. (65) demonstrated that the screw configuration plays an important role in converting the crystalline and the dissolution properties of solid dispersions. Nifedipine was used as a model drug, and hydroxypropyl methylcellulose phthalate (HPMCP) was the polymer. The authors reported that the kneading paddle elements of the screw affected the physicochemical properties of the extruded materials and generated transparent extrudates that exhibited super-saturation in dissolution tests. The kneading paddle elements retained the material in the extruder for a longer period under intense shear, and therefore, solid dispersions could be prepared irrespective of the operating conditions. In contrast, in their absence, the operating conditions of the machine such as the screw speed and amount of water added to the feed material significantly influenced the physicochemical properties of the extrudates. Slow screw speeds and the addition of optimal quantities of water increased the rate of drug dissolution but did not cause super-saturation (65).

He et al. (66) developed a solid dispersion of fenofibrate using HME technology to enhance the bioavailability of the API. These authors compared the effects of two different polymers including Eudragit ${ }^{\circledR}$ E 100 and polyvinylpyrrolidone-vinyl acetate copolymer S630 (PVP-VA) on the dissolution rate of fenofibrate. The extrudates were characterized using differential scanning calorimetry (DSC), X-ray diffractometry (XRD), in vitro dissolution testing, and in vivo bioavailability studies. The DSC and XRD results revealed that the fenofibrate was in a non-crystalline state in the solid dispersions of both polymers. The different solubility and gelling tendencies of the two polymers resulted in different dissolution profiles for the fenofibrate. Beagle dogs were the animal model used to compare the relative bioavailability of the Eudragit ${ }^{\circledR}$ E 100 solid dispersions with micronized Lipathyl® capsules, which was $177.1 \%$ (66).

Sathigari et al. (67) used HME technology to prepare solid solutions of efavirenz (EFV) with two different polymers including Eudragit ${ }^{\circledR}$ E PO or Plasdone ${ }^{\circledR}$ S-630 to improve the drug dissolution rate. The drug-polymer miscibility and processability using HME were confirmed by analyzing the thermal and rheological properties as a function of drug concentration. The

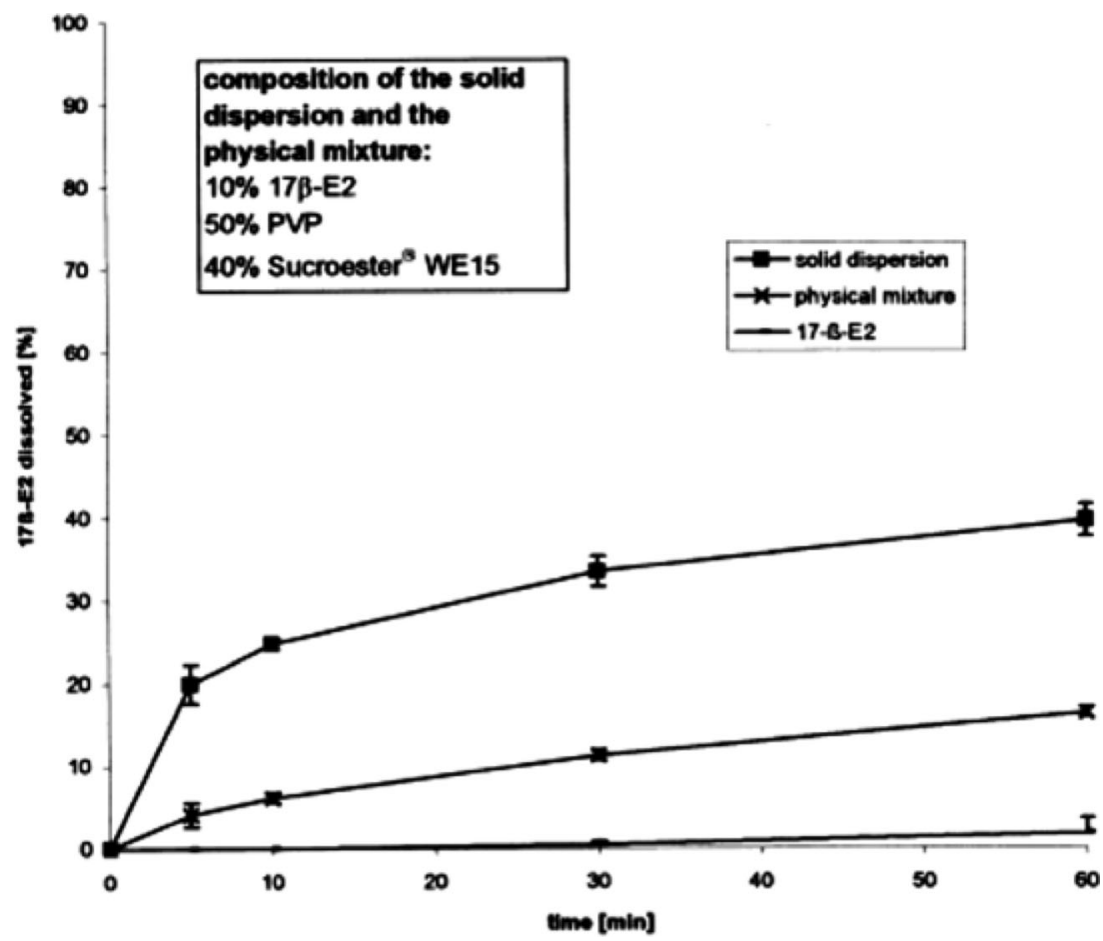

Fig. 5. Comparing a melt extruded solid dispersion, a physical mixture, and pure $17 \beta-$ estradiol (17 $\beta$ E2). Dissolution medium $0.1 \mathrm{~N}$ hydrochloric acid $(\mathrm{HCl})$. Reprinted with the permission from Hulsmann et al. (64) 
extrudates were further characterized using DSC, XRD, Fourier transform infrared spectroscopy (FTIR), and dissolution studies. The XRD and DSC results confirmed the existence of the amorphous form of EFV in the extrudates during storage. The EFV extrudates demonstrated a faster release profile than the crystalline drug did. The FTIR analysis showed an interaction between the EFV and Plasdone ${ }^{\circledR}$ S-630, which reduced the molecular mobility and prevented crystallization during storage (67).

Wang et al. (68) demonstrated the enhanced dissolution rate and oral bioavailability of Ginkgo biloba extract solid dispersions (GBE-SD) prepared via HME technology using a spray-dried powder carrier matrix, PVP-VA 64:Kolliphor® RH 40 (85:15). The in vitro release behavior of the GBE-SD showed a rapid dissolution of the drug with about $93 \%$ release in the first $20 \mathrm{~min}$. In contrast, the dissolution of GBE was significantly lower $(30 \%$ in $2 \mathrm{~h})$. The in vivo pharmacokinetic studies in male Sprague-Dawley rats showed that the maximum drug concentration $\left(C_{\max }\right)$ and area under the concentration-time curve (AUC) $0-t$ were more significantly increased following oral administration of GBE-SD than they were following oral administration of GBE. These results suggest that HME is a promising technology for the preparation of solid dispersions of natural product compounds with enhanced dissolution and oral bioavailability (68). These and other similar findings may have a substantial impact on the natural product industry by encouraging increased testing with the production of more efficacious products.

Alshahrani et al. (69) utilized HME technology in the preparation of carbamazepine (CBZ) solid dispersions using a novel combination of Soluplus ${ }^{\circledR}$ and the $\mathrm{HF}$ grade of the polymer hydroxypropyl methylcellulose acetate succinate (HPMCAS-HF, also called hypromellose acetate succinate in pharmaceutical applications) to enhance the solubility and physicochemical stability of the amorphous solid dispersion product. Soluplus ${ }^{\circledR}$ is polyethylene-glycol-polyvinyl caprolactam-polyvinyl acetate-grafted copolymer that was specifically designed and developed for HME by BASF SE. It is noteworthy that this innovation marked a significant milestone for HME because the substantial financial investment in this technology made by this multinational company for pharmaceutical applications demonstrated their confidence in the technology. The solid dispersions prepared were characterized using thermal gravimetric analysis (TGA), DSC, and attenuated total reflectance (ATR)-FTIR spectroscopy. The TGA results showed that the Soluplus ${ }^{\circledR}$, HPMCAS-HF, and $\mathrm{CBZ}$ were stable under the extrusion processing conditions used, and the DSC results indicated that molecular dispersions were formed when the drug loading was $40 \% \mathrm{w} / \mathrm{w}$ while higher drug concentrations resulted in the reappearance of CBZ crystalline peaks. The FTIR data demonstrated that the intensity of the hydrogen bonding was increased by the addition of HPMCAS-HF, which worked synergistically with the Soluplus ${ }^{\circledR}$ to enhance the solubility and stability of the formulation. These researchers also studied the effect of the polymer ratio on the extrudability and dissolution profile and found that the release of CBZ was enhanced with an increase in the percentage of Soluplus ${ }^{\circledR}$ (69).

As evidenced by the above studies, HME is an extremely viable technique for the formation of solid dispersions that may increase the dissolution rates of poorly soluble APIs and more importantly increase their bioavailabilities.

\section{Microencapsulation}

The microencapsulation of materials is an alternative to traditional methods for ensuring that the enclosed material reaches the desired area without being adversely affected by the harsh systemic environment through which it passes. Microcapsules are the end product of this process and they are available in various morphologies including the single phase, which has the encapsulant dissolved in the matrix; two phase, which has the encapsulant dispersed in the matrix; and the multiple phase, which consists of two non-miscible matrix components. In this case, the encapsulants are either dissolved or dispersed within the matrix. Encapsulation via HME exhibits several benefits including the minimal use or absence of solvents, cost-effective techniques, and the potential for a continuous manufacturing process.

There are numerous reports of the use of microencapsulation to enhance the targeted release of drugs. For instance, Mehuys et al. (70) developed a sustained-release system consisting of hot-melt extruded ethyl cellulose cylinders containing an HPMC-Gelucire core. This is an example of a coreshell type microcapsule system prepared via HME technology. Different types and viscosity grades of HPMC were utilized, and all the systems demonstrated only a $40 \%$ drug release over a 24-h period, which was increased by shortening the length of the ethyl cellulose cylinder. However, a change in the cylinder diameter had no effect on the drug release rate. In addition, the drug solubility did not affect its release rate or mechanism (70).

In another study, Mehuys et al. (49) used HME as an alternative technique for enteric drug delivery. Polyvinyl acetate phthalate (PVAP) and HPMCAS as an enteric-coated polymer were premixed with the plasticizers and extruded into hollow cylinders. The hollow cylinders were then filled with the model drug and both open ends were sealed. The dissolution profile of the final product demonstrated that no drug was released following exposure to $0.1 \mathrm{~N}$ hydrochloric acid $(\mathrm{HCl})$ for $2 \mathrm{~h}$, indicating that the enteric coating was successful and provided the dosage form with gastro-resistance (49). Indeed, microcapsules have been demonstrated to be successful as formulations for avoiding drug release in the drug-hostile environment of the gastrointestinal tract (GIT).

\section{Targeted Drug Delivery}

Developing drug delivery systems involves incorporating technological designs that maximize the therapeutic efficacy of drugs by controlling their biodistribution profiles. To achieve this purpose, the delivery system is required to have an optimal selectivity and specificity towards the target tissues or cells (71). Various techniques have been developed for targeted drug delivery over the past few years, and currently, researchers have focused on HME as a promising and feasible option.

Bruce et al. (72) used the HME technology for the targeted colonic delivery of 5-aminosalicylic acid (5-ASA). They prepared hot-melt extruded tablets of 5-ASA using Eudragit ${ }^{\circledR}$ S 100 as the polymeric carrier, and the effect of adding two plasticizers including triethyl citrate (TEC) and citric acid was studied. The TEC reduced the processing temperature and influenced the drug release rates, caused by 
leaching from the tablets, which was observed during the dissolution testing (Fig. 6). Furthermore, the citric acid content decreased the $\mathrm{pH}$ of the micro-environment of the tablet and, thereby, suppressed the polymer ionization and resulted in slower drug release rate (72).

Miller et al. (73) improved the oral absorption of itraconazole (ITZ) by the targeted intestinal delivery of the supersaturated drug formulated using HME. The amorphous solid dispersions of ITZ in Eudragit ${ }^{\circledR}$ L 100-55 containing either 20 or $40 \%$ Carbopol $\AA 974 \mathrm{P}$ obtained were analyzed using DSC and XRD while the dissolution analysis was conducted using a $\mathrm{pH}$ change method. The in vivo evaluation of the solid dispersion was performed in male Sprague-Dawley rats, and the results showed that the addition of Carbopol® 974P substantially reduced the absorption variability with the Eudragit ${ }^{\circledR}$ L 100-55 carrier system. Therefore, intestinal targeting of ITZ was successfully achieved with the HME technology (73).

Cassidy et al. (74) achieved the targeted drug delivery of a photosensitizer to the colon via a formulation prepared using HME. The authors used Eudragit ${ }^{\circledR}$ S 100 as a polymer, and the formulation composed of the drug, polymer, photosensitizer, and the plasticizer, TEC, was extruded using a TSE. Photodynamic antimicrobial chemotherapy (PACT) is a novel treatment option for multidrug-resistant organisms such as Enterococcus faecalis and Bacteroides fragilis inhabiting the colon. The results of this study showed that no drug was released in the acidic medium. The authors demonstrated with these formulations that photosensitizer release could potentially be targeted to the colon, and therefore, the pathogen resident there could be killed by PACT (74).

The studies mentioned in this section have clearly illustrated the improvements in bioavailability that have been

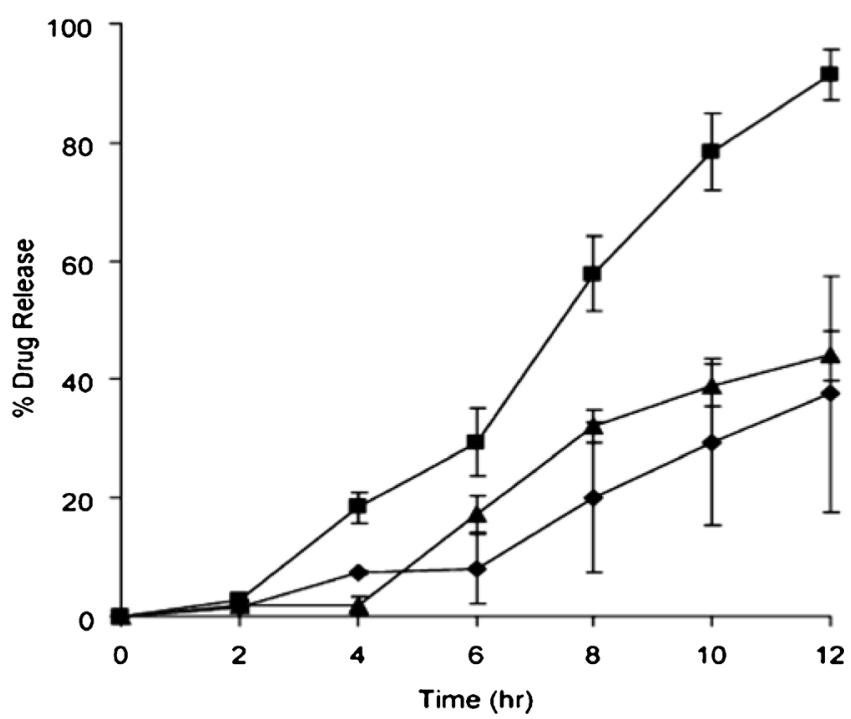

Fig. 6. Influence of triethyl citrate (TEC) concentration and preplasticization on drug release rate of hot-melt extruded tablets containing 25\% w/w 5-aminosalicylic acid (ASA). black triangle Formulation A2, pre-plasticized $12 \% w / w$ TEC; black diamond formulation A1, no pre-plasticization $12 \% \mathrm{w} / \mathrm{w}$ TEC; and black square formulation B, preplasticized 23\% w/w TEC. Dissolution medium consisted of $0.1 \mathrm{~N}$ hydrochloric acid $(\mathrm{HCl}) \mathrm{pH} 1.2$, from 0 to $2 \mathrm{~h} ; 50 \mathrm{mM}$ phosphate buffer $\mathrm{pH}$ 6.8, from 2 to $6 \mathrm{~h}$; and $\mathrm{pH} 7.4$, from 6 to $12 \mathrm{~h}$ at $37^{\circ} \mathrm{C}$ and $100 \mathrm{rpm}$, apparatus $2(n=3)$. Reprinted with permission from Bruce et al. 2005 (72) achieved using targeted drug delivery systems formulated via HME processes. Furthermore, the invaluable features of HME technology have been demonstrated as a potential drug delivery processing tool.

\section{Taste Masking}

Numerous active ingredients used in pharmaceutical preparations have an unpleasant bitter taste. When drug molecules dissolve in saliva, they interact with the taste receptors on the tongue to produce bitter, sweet, or other taste sensations as a result of signal transduction from the taste receptor organs also called taste buds. These taste buds have very sensitive nerve endings, which produce and transmit electrical impulses via the seventh, ninth, and tenth cranial nerves in the areas of the brain devoted to the perception of taste. Therefore, taste masking is essential for improving the palatability of bitter-tasting drugs. There are two approaches commonly used to overcome unpleasant tastes. The first involves decreasing the solubility of the drug in the saliva by converting it from the amorphous to the crystalline form. The second involves altering the interaction between the drug and taste receptors $(75,76)$. HME has been used as a taste-masking technique for bitter active ingredients by the formulation of solid dispersions with a taste-masking polymer. These solid dispersions prevent the release of bitter drugs in the saliva and, therefore, prevent the interaction between the drug molecules and taste bud (77-80). Taste masking can be achieved via hydrogen bonding between the active ingredient and the polymer matrix by processing oppositely charged compounds $(75,81,82)$.

Gryczke et al. (76) developed orally disintegrating tablets (ODTs) containing ibuprofen (IBU) granules using HME technology (76). The objective of their study was to increase the dissolution rate of IBU and incorporate the taste-masked granules in the ODT formulation. The HME process was conducted at $140^{\circ} \mathrm{C}$, to produce smooth extrudates at two different IBU loading levels of 25 and $40 \%$. Eudragit ${ }^{\circledR} \mathrm{E}$ $\mathrm{PO}$ was selected as the primary matrix-forming polymer, and plasticizers were not used in this formulation because IBU has been shown to possess plasticizing effects comparable to traditional plasticizers (52). The extrudates were analyzed using XRD to examine the IBU crystallinity, and the results showed that even at the high drug loading (40\%) level, IBU remained in an amorphous state. The presence of a single $T_{\mathrm{g}}$ confirmed the complete miscibility of IBU and E PO as well as the creation of a glassy solution in which IBU was molecularly dispersed within the E PO $(76,82)$. The in vivo taste-masking evaluation showed that the HME processing efficiently masked the bitter taste of the active ingredients without compromising the tablet palatability. The developed ODTs showed a disintegration time and crushing resistance similar to the commercial Nurofen ${ }^{\circledR}$ tablets but with an improved tablet friability. In addition, the enhanced IBU release rate of the developed ODTs was faster than that of the commercial Nurofen ${ }^{\circledR}$ tablet was.

Maniruzzaman et al. (80) used the HME technique to mask the taste of paracetamol by preparing it as a blend with Eudragit ${ }^{\circledR}$ E PO and Kollidon ${ }^{\circledR}$ VA 64 using a Turbula TF2 mixer. The Rand castle SSE was used to extrude the paracetamol blend. Different drug/polymer compositions were used 
(drug/E PO and drug/VA 64 at ratios of 40/60, 50/50, and 60/40 and 30/70, 40/60, and 50/50, respectively). The extruded paracetamol granules were then evaluated in vivo for tastemasking efficiency using a panel of six healthy human volunteers. In addition, they used the e-tongue equipped with seven sensors for the in vitro evaluation. The data obtained were compared with that of the placebo polymers and pure drug. The authors observed that the taste was improved with both polymers used in this study. The best taste-masking effect was observed with Kollidon ${ }^{\circ}$ VA 64 at 30\% drug loading (Fig. 7) (80).

Morott et al. (83) demonstrated the use of HME as an effective tool for masking the bitter taste of sildenafil citrate by embedding it in ethyl cellulose along with a $\mathrm{pH}$-dependent pore former such as calcium carbonate. The pore former prevented oral drug dissolution (at $\mathrm{pH}$ 6.8) and promoted gastric drug dissolution (at $\mathrm{pH} 2.0$ ). The study also showed that different screw configurations profoundly affected the taste-masking efficacy of the formulation because of alterations in the physical state of the API. This study used three screw configurations including one with all conveying elements, one with three mixing zones, and one with a shorter screw design $(25: 1 L / D)$ with one mixing zone (Fig. 8). The all conveying element screw design preserved a considerable portion of the crystalline phase of the API, but there was still a noticeable presence of the amorphous form in the carrier. The shorter screw design with one mixing zone enhanced the preservation of the API crystalline nature (83). These and

a

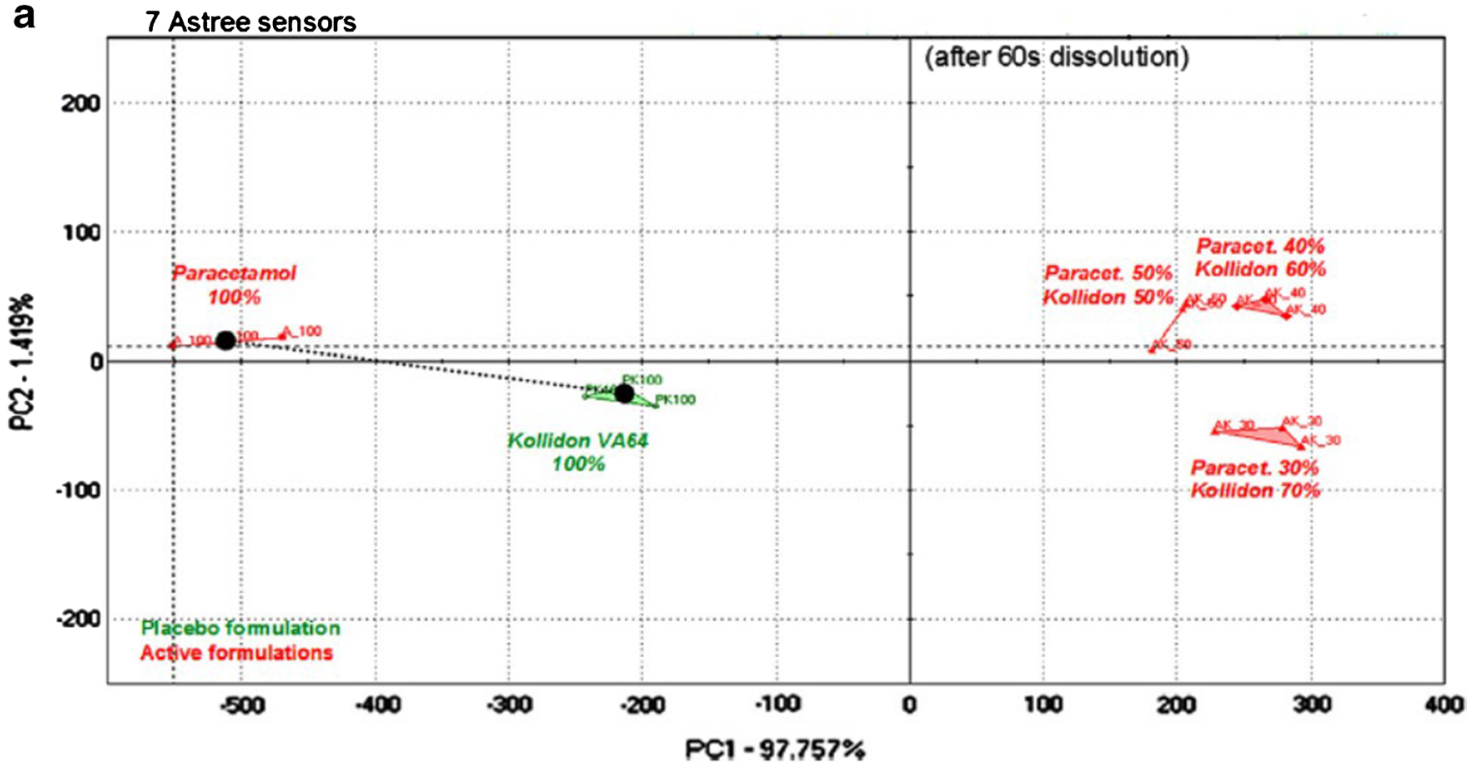

b

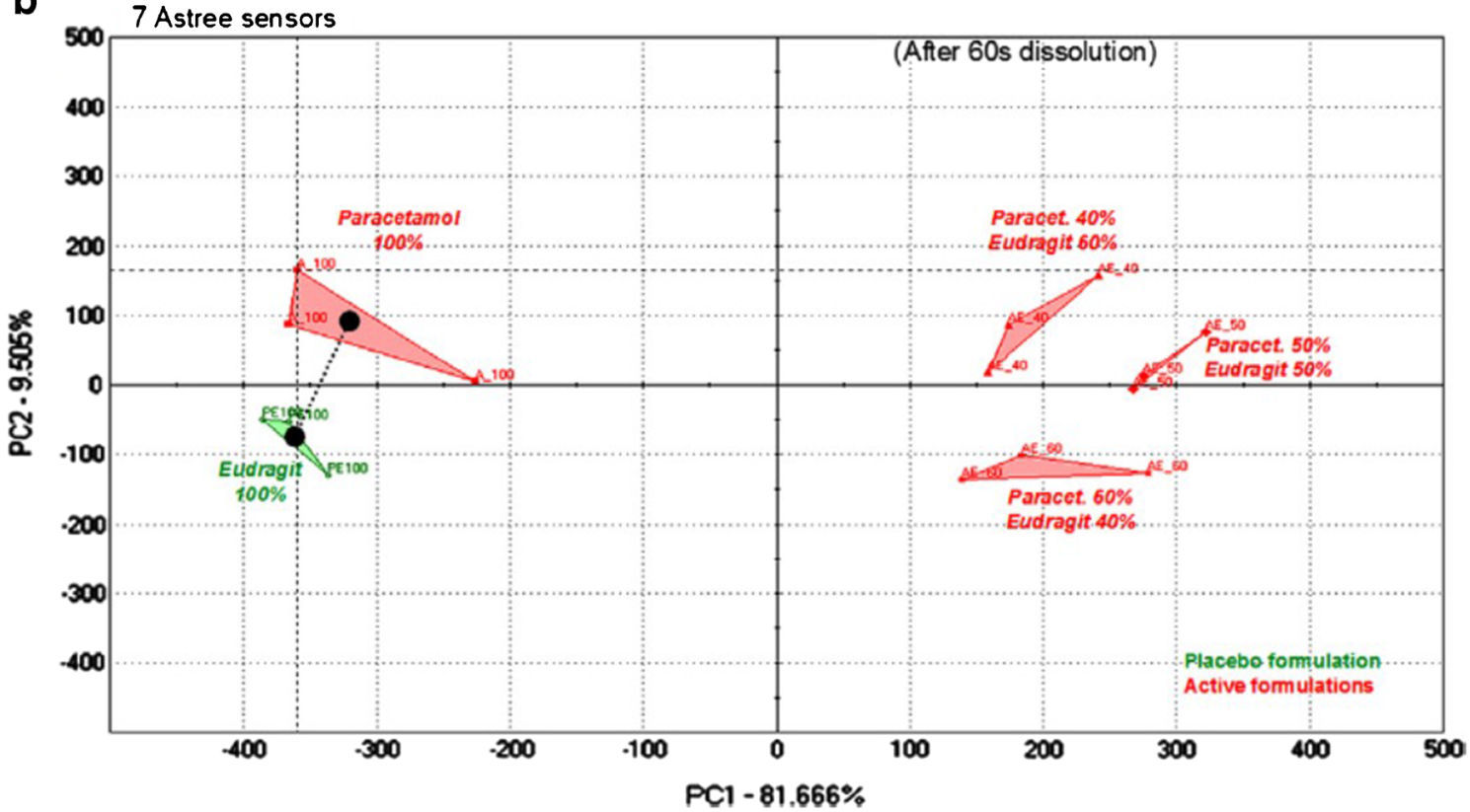

Fig. 7. Electronic tongue "taste map." Comparison of global signal (principal component analysis, PCA, of the electrode responses) between pure paracetamol and extruded formulations to a VA 64 polymer and b Eudragit ${ }^{\circ}$ E PO polymer after dissolution for $60 \mathrm{~s}$. Reprinted with permission from Maniruzzaman et al. (80) 
a

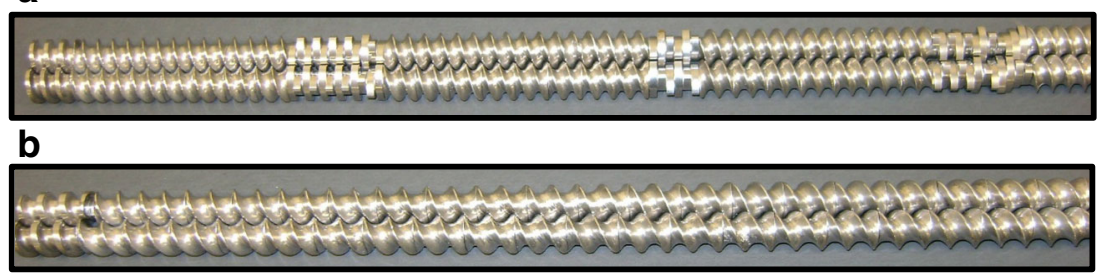

C

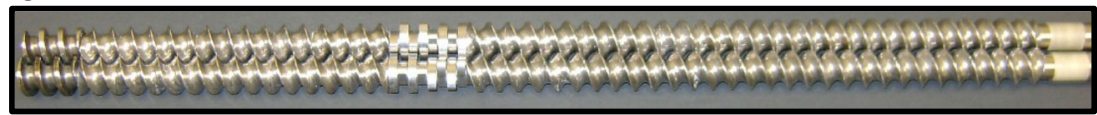

Fig. 8. Images of three screw configurations evaluated during hot-melt extrusion (HME) process optimization. a Thermo Fisher "standard configuration," 40:1 L/D. b All conveying elements, 40:1 L/D. c From left to right, $110 \mathrm{~mm}$ of conveying elements, $22 \mathrm{~mm}$ of perpendicularly arranged mixing elements, and $165 \mathrm{~mm}$ of conveying elements $25: 1 \mathrm{~L} / \mathrm{D}$ (83)

other similar studies, therefore, provide convincing evidence that the HME process can be successfully used as an alternative taste-masking technique for bitter APIs.

\section{Films}

Films can be defined as thin sheets containing one or more polymers with or without a plasticizer, and they may be used as a drug delivery system or directly applied to wounds as a dressing to facilitate a therapeutic healing effect. Current film manufacturing technologies are mainly based on solvent-casting approaches. The hazardous nature of most organic solvents, residues even after drying, and complicated processing conditions limit the selection of appropriate solvents while the disposal of the associated waste may pose an environmental health hazard $(48,84,85)$. Therefore, to overcome the limitations of solvent-casting methods, HME technology is currently used to prepare films in the pharmaceutical industry, and various aspects of this technology have been extensively studied by numerous research groups.

Repka et al. (41) investigated the effect of plasticizers and drugs on the physicomechanical properties of hot-melt extruded hydrophilic films. Hydrocortisone or chlorpheniramine maleate $(1 \%$ each) was used as a model drug. The HPC (Klucel ${ }^{\circledR}$ ) films were prepared with the drug, and plasticizing agents such as PEG 8000, TEC, acetyl tributyl citrate, and PEG 400 were then evaluated for tensile strength, percentage elongation, and Young's modulus. These investigators concluded that HME was a feasible process for preparing thin, flexible, and stable HPC films. However, without a plasticizer or a processing aid, the HPC films could not be produced because of the high stress generated in the extruder (41).

In another study by Repka et al. (86), oral mucoadhesive lidocaine-containing films were prepared with a combination of two cellulosic polymers HPC and HPMC, as the matrixforming polymer and drug-release modifier, respectively, using the HME process. Two formulations were prepared with one loaded with only HPC and the other with HPC:HPMC (80:20) and the homogeneous films produced had an average thickness of $0.66 \pm 0.01 \mathrm{~mm}$. The bioadhesive testing of both films was performed using the TA.XT2i texture analyzer, and the results showed that the HPC:HPMC film had a greater area under the curve (work of adhesion) and a higher peak adhesive force than the HPC film did. This is because the
HPMC is more hydrophilic, which allows a faster hydration interaction with the mucin membrane. The polymer hydration leads to chain mobilization followed by interpretation and physical entanglement following contact with the mucin membrane due to the hydroxyl group interactions (Fig. 9) (86).

Mididoddi and Repka (87) investigated a specific application for antifungal HME films in the treatment of the nail infection onychomycosis (87). In onychomycosis, targeted local drug delivery via a bioadhesive film improves patient compliance because oral and other systemically administered antifungal therapies require long-term treatment, and patients often experience systemic side effects (88). In addition, the study investigated the physicochemical properties and stability of the model antifungal agent incorporated in the films (87). The films, which contained HPC, PEO, or both in combination with $20 \%$ ketoconazole, were extruded using a Killion extruder and analyzed using DSC, scanning electron microscopy (SEM), and XRD. The bioadhesive properties of the films were investigated on the human nail (ex vivo) using a texture analyzer (87).

Low et al. (88) studied the effect of varying the ratio of the solubilizing (Kollidon ${ }^{\circledR}$ VA 64 or Soluplus $\left.{ }^{\circledR}\right)$ and filmforming (HPC) polymers on the mechanical properties and release rates of hot-melt extruded orodispersible films (ODFs) using a $2^{3}$ factorial design. Chlorpheniramine and indomethacin were used as model drugs, and the results showed that the drug and the two-way interaction between the drug and solubilizing polymer exerted the main effects on the mechanical properties of the film. In contrast, the main impacts on the release rates were exerted by the solubilizing polymer, the drug, and the two-way interaction between the solubilizing polymer and the ratio of solubilizing polymer to the film-forming polymer. While the Kollidon ${ }^{\circledR}$ VA 64 containing films showed a better drug release profile, the Soluplus ${ }^{\circledR}$ films exhibited better mechanical properties (88).

Palem et al. (89) prepared bioadhesive domperidone buccal immediate-release films using HME technology with either PEO N10 alone or in combination with HPMC E5 and LV or Eudragit ${ }^{\circ}$ RL PO or both as the polymer matrix. In addition, PEG 3350 was used as a processing aid with $10 \%$ drug loading. The produced films were smooth in appearance, uniform in thickness $(810-850 \mu \mathrm{m})$, and the drug content indicated a favorable drug loading and ranged from 96.5 to $99.2 \%$. In addition, there were no visible cracks in the films, the 

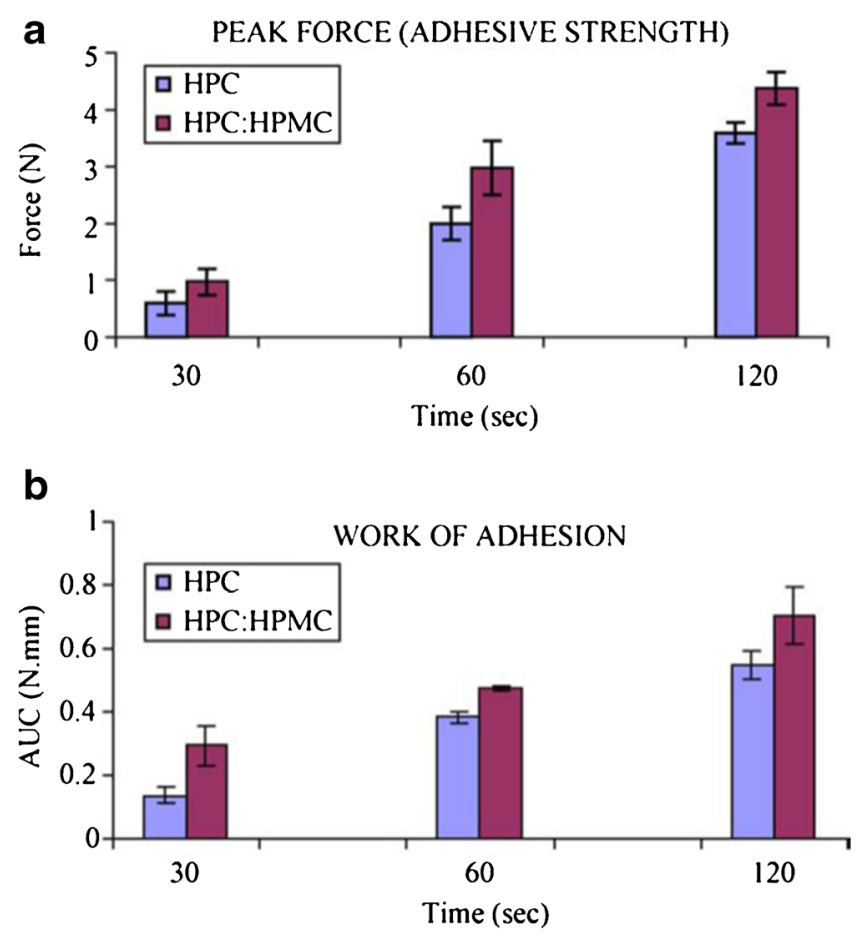

Fig. 9. a Peak force (adhesive strength) and b work of adhesion of hydroxypropylcellulose (HPC) and HPC:hydroxypropyl methylcellulose acetate succinate (HPMC) films measured using a texture analyzer and rabbit intestinal mucosa as a substrate $(n=5) ; A U C$ area under the curve. Reprinted with permission from Repka et al. (86)

maximum tensile strength was $0.87 \mathrm{~kg} \cdot \mathrm{mm}^{-2}$, and the elongation at break was $40.8 \% \mathrm{~m}^{2}$, which indicated that an ideal buccal film can be produced by HME (89).

Chen et al. (90) investigated the effect of processing parameters and formulation factors on the bioadhesive properties, the thermostability, and the drug release profile of miconazole in POLYOX ${ }^{\circledR}$ and Klucel ${ }^{\circledR}$ matrix systems film developed using the HME process. This study demonstrated that the bioadhesive property of the miconazole film was mainly affected by the polymer blend ratio, the barrel temperature, the extruder screw speed, and the contact time with the mucosal tissue. The XRD analysis performed in the stability study showed an absence of recrystallization indicating the stability of miconazole in the Klucel ${ }^{\circledR}$ matrix system over a period of 8 months (90).

Although solvent casting is a traditional method of film preparation widely used by formulation scientists, the HME process can also be successfully implemented for this purpose and has immense potential for the development of robust film formulations.

\section{Implants}

Implantable medical devices are widely used in the pharmaceutical industry. Recently, HME technology has been applied as a viable new method for preparing implantable devices, as evidenced by the numerous studies reporting its versatility and advantages. In addition, other studies have highlighted the critical factors and parameters that ensure a successful HME process in the preparation of implantable devices.

Rothen-Weinhold et al. (91) used HME technology to prepare long-acting PLA implants containing vapreotide, a somatostatin analogue, but the peptide degraded during the process due to the formation of a lactoyl-vapreotide conjugate. The authors discovered that the presence of a residual lactide in the PLA significantly influenced the formation of the peptide impurity, which illustrates that the purity of the carrier used is an essential factor to be considered in developing a quality dosage form (91).

Ghalanbor et al. (92) studied the feasibility of using HME in the preparation of implants based on protein/PLGA formulations with special emphasis on the protein stability, burst release, and release completeness. In this study, hen egg white lysozyme was chosen as the model protein. The stability of the lysozyme was confirmed using DSC, FTIR, high-performance liquid chromatography (HPLC), and biological activity determination. The results showed that the lysozyme retained its full biological activity after the HME process, and the in vitro release of the enzyme persisted for 60-80 days. The recovery of the active lysozyme was nearly complete, which illustrated that the HME process did not alter protein integrity. These researchers, therefore, concluded that HME is a promising method for the effective delivery of protein therapeutics because of its relative simplicity, single-step formulation process, and good protein stability (92).

In another study by the same group, they used bovine serum albumin (BSA) as a model drug to prepare BSAPLGA implants using HME with a special focus on identifying the reasons for incomplete release (93). The implant was prepared using a syringe-die extrusion device. A burst-free release was achieved with up to $25 \%$ BSA loading by milling the protein before extrusion. The drug release was increased up to $97 \%$ by high-protein loading. According to the study results, the PLGA-protein interaction mediated by the free cysteine residues of the protein may be one of the reasons for the incomplete release of protein from PLGA delivery systems. This notion was corroborated by the results of their previous study since the lysozymes used there had no free cysteine residue and were released completely from the PLGA implant (92).

Li et al. (94) investigated the use of the HME technology in preparing dexamethasone-loaded implants using polymers such as PLA and PEG-block-poly(propylene glycol)-blockPEG copolymer (PEG-PPG-PEG, Pluronic F68). The drugimplant device compatibility was studied using DSC while mass loss and SEM techniques were used to confirm the degradation behavior of the implants. The implant drug loading and encapsulation efficiency were found to be up to 48.9 and $97.9 \%$, respectively. The in vitro results showed that the controlled drug release persisted over 120 days. Furthermore, the implant device degraded faster in an alkaline solution (94).

Stakovic et al. (95) investigated the effect of novel biodegradable phase separated poly(e-caprolactone)-PEG-blockpoly(e-caprolactone) (PCL-PEG-b-PCL) multiblock copolymers with different block ratios and low melting temperatures $\left(49-55^{\circ} \mathrm{C}\right)$ on the in vitro release of protein from implants prepared using HME. The proteins were spray-dried with inulin as a stabilizing agent to obtain a uniform particle-sized 
spray-dried protein, which was then incorporated in a polymeric implant via HME. Analysis of the final implant product showed that the release rate of the protein increased with a decrease in the molecular weight of the protein and increase in the PEG content of the polymer. Further, the PEG content also influenced the swelling and degradation rate of the copolymer. Therefore, these results suggest that the release rate of protein of varying molecular weight from PCL-PEG-b-PCL multiblock copolymers can be controlled by changing the PEG content of the polymer (95). The studies highlighted in this section demonstrated that biodegradable implants could be prepared successfully via HME and further revealed the added advantage of facilitating high drug loading of the device.

\section{Sustained-Release Preparations}

Sustained-release formulations are designed to release their drug content at a predetermined rate, time, and often location, to provide the advantage of a consistent and constant concentration of the drug with fewer side effects. Different methods have been used to achieve varying degrees of sustained release. HME has also been explored for use in the formulation of this drug delivery system with the intention of incorporating the versatility and advantages of this technology in improving both the methods of preparation and outcome of final sustained-release products. To this effect, a number of studies have investigated the effects of the various technological process parameters, materials, and innovations that have been used to prepare these drug delivery systems using HME.

Using the HME technology, Verhoeven et al. (96) produced sustained-release mini-matrices and studied the influence of the formulation and process parameters on their drugrelease characteristics. Metoprolol tartrate (MPT) was used as a model drug, ethyl cellulose the sustained-release polymer, dibutyl sebacate the plasticizer, and xanthan gum the hydrophilic polymer. The xanthan gum showed the most significant effect on the in vitro drug release profile, and a faster drug release was observed when the concentration was increased from 1 to $20 \% w / w$ while a zero-order drug release was obtained at $5 \% w / w$. The authors observed that for smooth and homogeneous extrudates, at least one mixing zone was required. However, the number of mixing zones or their positions along the extruder barrel did not have any effect on the mixing efficacy and drug release. The Raman spectroscopy results showed that the drug was homogeneously distributed in the mini-matrices, irrespective of the screw design and processing conditions used. In addition, the authors demonstrated that the feed rate and screw speed did not alter the extrudate quality or the dissolution profile of the drug (96).

Ozguney et al. (97) developed and characterized extended release mini-matrices prepared using HME technology, with IBU and theophylline as model drugs and Kollidon ${ }^{\circledR}$ $\mathrm{SR}$ as the polymeric carrier. A TSE was used to extrude the powdered mixture containing the Kollidon ${ }^{\circledR} \mathrm{SR}$. The $T_{\mathrm{g}}$ and maximum torque were inversely related to the IBU concentration, which indicated its plasticizing effect. In addition, the authors observed that the percentage drug loading for both APIs played an important role in the drug release rate. Moreover, an increase in the extrusion temperature decreased the release rate of the hot-melt extruded theophylline and increased that of the IBU. This observation supported the notion that IBU exerted a plasticizing effect on the Kollidon ${ }^{\circledR}$ SR. The authors also observed a decrease in the theophylline release rate with an increase in the TEC concentration while the addition of Klucel ${ }^{\circledR}$ LF increased the release rate of both IBU and theophylline (97).

Almeida et al. (98) demonstrated that ethylene vinyl acetate (EVA) and PEO polymers facilitate the sustained release of APIs from the HME matrices. EVA samples with varying vinyl acetate (VA) contents of $9,15,28$, and $40 \%$ were used with MPT as the model drug and PEO as the swelling agent to prepare the EVA/MPT/PEO formulations using HME. The drug release profile, solid-state characteristics, porosity, and polymer miscibility of the EVA/PEO matrices of the HME formulation were then evaluated using DSC, Xray tomography, and Raman spectroscopy (98).

\section{Nanotechnology}

The primary advantages of the nanotechnology-based drug delivery system are as follows: (1) improved bioavailability by enhanced aqueous solubility, (2) prolonged drug presence in the body (increased half-life for clearance), (3) targeted drug delivery to a specific location in the body, (4) enables the incorporation of both hydrophilic and hydrophobic APIs, and (5) high carrier capacity. Nanotechnology-based drug delivery systems such as solid lipid nanoparticles (SLNs), nanosuspensions, nanocrystals, and nanoemulsion have been previously prepared using several traditional batch-based methods. Currently, HME has been used to produce nanotechnology-based products in a continuous process, which reduces the variability in the performance of the final product, saves processing time, and reduces product cost. There are numerous reports in the literature supporting the feasibility and advantages of continuous processing-based HME technology in the production of nano-based drug delivery systems.

The study by Patil et al. (8) is an excellent example of the successful application of HME in the production of a continuous SLN using QbD principles and the design of experiment approach. This study highlighted the application of HME in conjunction with a high-pressure homogenizer to produce SLN as a drug carrier system (Fig. 10). The model drug used in this study was fenofibrate, which is a biopharmaceutical classification system II (BCS class II) poorly water-soluble drug with poor bioavailability. The particle size of the preemulsions produced using the HME and a conventional method was 653 and $1643 \mathrm{~nm}$, respectively. The conventional method would require a high number of cycles and pressure to reduce the particle size to less than $200 \mathrm{~nm}$. Therefore, an additional advantage of the HME process is that it produces a pre-emulsion with a particle size already in the low nanometer range and, therefore, requires less downstream processing with the high-pressure homogenizer. The in vivo pharmacokinetic study showed that the plasma concentration of the metabolite fenofibric acid was significantly higher $(P 0.05)$ in rats treated with fenofibrate SLN than it was in those treated with the crude and commercially available fenofibrate (99).

Baumgartner et al. (100) identified a potential use for HME by designing and developing a one-step nanoextrusion 


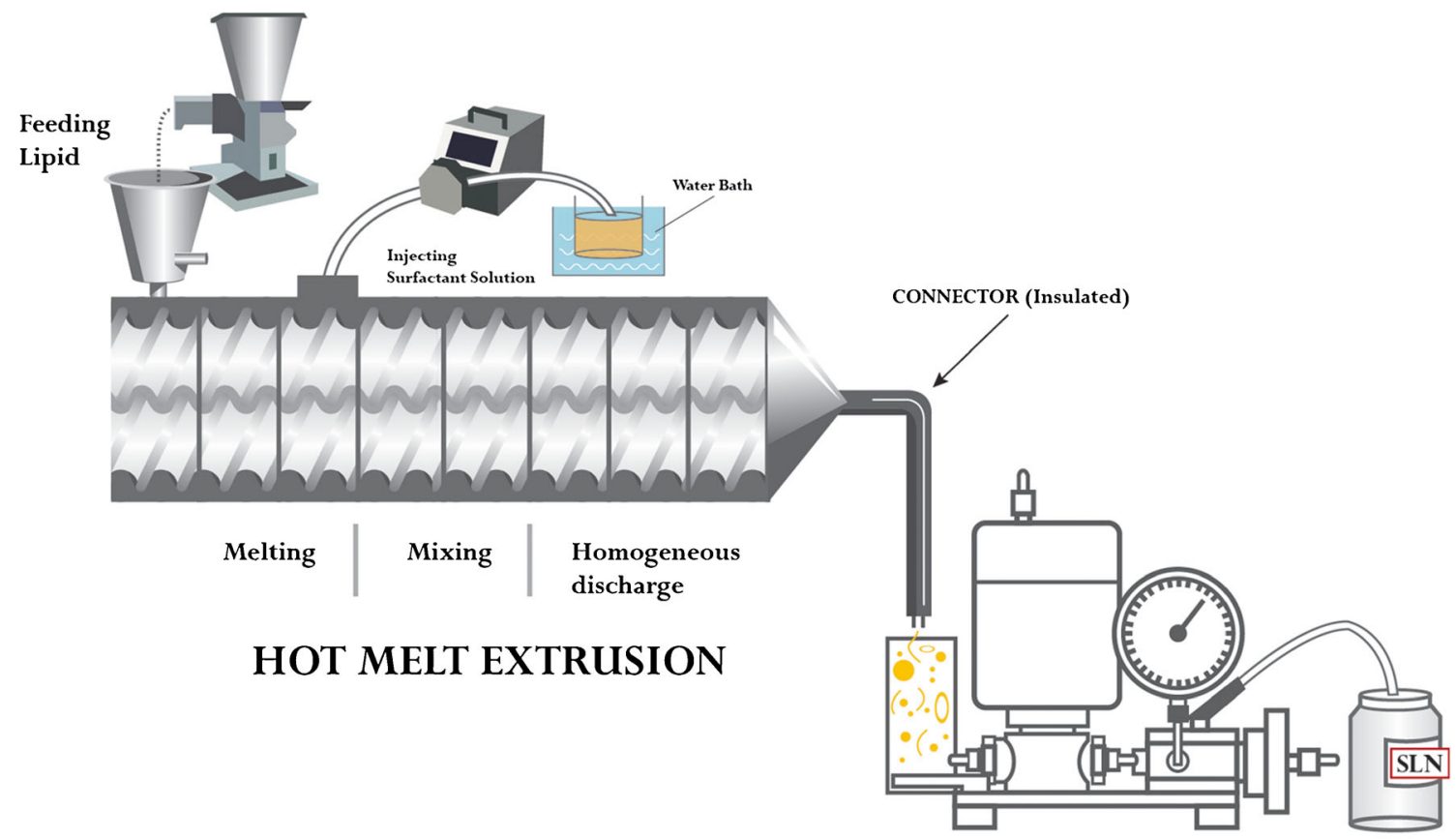

High Pressure Homogenization

Fig. 10. Schematic representation of continuous preparation of solid lipid nanoparticles (SLNs) using hot-melt extrusion connected to a high-pressure homogenizer (99)

process for manufacturing solid nanoparticle formulations by directly feeding the nanosuspension into the HME equipment, and the solvent was finally removed continuously via devolatilization. The authors used phenytoin as the waterinsoluble model drug and Soluplus ${ }^{\circledR}$ as the polymer. A more significant increase was observed in the solubility of the phenytoin formulated as a nanosuspension and later as a nanoextrudate than in that of the bulk phenytoin powder. The prepared solid nanoformulations showed an increased dissolution rate $(100 \%$ drug release in $5 \mathrm{~min})$ due to an increased effective particle surface area (100).

\section{Floating Drug Delivery System}

The discovery and development of the floating dosage form offered potential advantages for drugs with poor bioavailability due to their absorption being restricted to upper GIT, because this dosage form maximizes absorption and improves the absolute bioavailability of drugs. Over the last few decades, formulation scientists have used various approaches to produce effervescent and non-effervescent floating drug delivery system (FDDS) to extend the residence time of drugs in the stomach (101).

Fukuda et al. (102) investigated the influence of sodium bicarbonate on the physicochemical properties of controlledrelease hot-melt extruded tablets containing acetohydroxamic acid, chlorpheniramine maleate, or both and polymers such as Eudragit ${ }^{\circledR}$ RS PO, Eudragit ${ }^{\circledR}$ E PO, or both. In this study, the incorporation of sodium bicarbonate did not influence the drug release rate. However, the inclusion of sodium bicarbonate reduced the density of the HME tablets to less than $1 \mathrm{~g}$ / $\mathrm{cm}^{3}$ suggesting that the HME tablet would float. It was concluded that the porous internal tablet morphology contributed to the buoyancy that was created by the generation of carbon dioxide $\left(\mathrm{CO}_{2}\right)$ gas in $0.1 \mathrm{~N} \mathrm{HCl}$. This enhanced buoyancy was attributed to the thermal decomposition of the sodium bicarbonate in the softened acrylic polymer, which occurred during the hot-melt extrusion processing (102).

\section{HME AS A CONTINUOUS PHARMACEUTICAL MANUFACTURING PROCESS}

Tablets are the most popular solid dosage forms in use today and about two thirds of all prescriptions dispensed are solid dosage forms, half of which are tablets. To ensure the homogeneous distribution of the active ingredient in each tablet, wet granulation has been the most commonly used manufacturing process especially as it improves the flow properties, reduces dust and segregation of particles, and improves the compressibility of the powder mix (103). The most common techniques used for wet granulation are the high shear and fluid bed granulation. Because wet granulation is an important step in the tablet manufacturing, there is an increasing need for alternative techniques that can enhance this process and render it more economic, reliable, and reproducible taking into consideration the possibility of automation and process continuity.

The increasing demand for solid dosage forms including tablets and the need for more efficiency in their production have shifted the focus and interest of the pharmaceutical industry to the numerous benefits and advantages that continuous manufacturing processes have over traditional batch processes. Continuous production processes are based on the "one-in-one-out" principle and, therefore, have a larger production capacity, reduce production cost, ensure faster product release, save on space and labor, avoid scale-up problems, 
and improve product quality $(98,103)$. Therefore, a number of studies on the feasibility of incorporating HME techniques in wet granulation methods and the factors influencing the final product outcome have reported successful innovations, and the following are a few highlighted examples.

The benefits of using TSE for wet granulation in the pharmaceutical industry were first identified by Gamlen and Eardley (104). Lindberg et al. (105) used a TSE to prepare paracetamol effervescent granules and observed that their properties were influenced by formulation and process variables (105). Kleinebudde and Linder (13) also studied the TSE/granulation process using lactose/microcrystalline cellulose. In addition, several research groups have investigated the HME technique as a tool for continuous pharmaceutical granulation processes (13).

Ghebre-Sellassie et al. (106) filed a patent application for a continuous granulation method using a TSE (106) while Keleb et al. (107) also investigated the use of a continuous TSE in the wet granulation of lactose, which was then compared with the conventional high shear granulation method (107). It was concluded that the HME technique was a robust process that might offer a suitable alternative to high shear granulation in the pharmaceutical industry for the wet granulation step. This study also investigated the effects of the process parameters (screw speed and input rate) and formulation variables (water and PVP concentration) on the properties of the granules produced such as yield, particle size distribution, friability, and compressibility with favorable results.

Van Melkebeke et al. (103) in 2008 studied the effect of modifying the screw configuration on granule quality, tablet properties, and mixing efficiency in TSE granulation. The number of mixing zones and configuration of the kneading blocks were used as variables in modifying the screw configuration. Changing the staggering angle of the kneading element significantly affected the yield and friability of the granules while the disintegration time was the only tablet property significantly influenced by the screw configuration, since it was observed to be significantly faster when an extra conveying element was placed at the end of the screw (103). These researchers observed a good mixing efficiency, which was independent of the tracer addition method, trace solubility, granulation time, and granule size, and, therefore, concluded that continuous granulation using a TSE was a robustly adequate process.

In a recent study, $\mathrm{Mu}$ and Thompson (108) investigated the mechanisms of a hot-melt granulation process described for high shear mixers and fluidized bed that can be equally applied to (108) TSE granulation processes. The co-rotating intermeshing TSE was used to prepare the granules, and two different PEGs were used as model binders. The authors studied the effect of different variables such as the screw design, the binder content, the binder molecular weight, and the process temperature on granule development. They also observed that using $60^{\circ}$ offset kneading blocks progressively increased the residence time and axial dispersion, with the number of mixing zones created inside the extruder.

\section{SCALE-UP OF HME PROCESSES}

HME is a continuous manufacturing process, but because only limited amounts of the API are available at the early development stages, extrusion of smaller batch sizes is the preferred approach used in the pharmaceutical industries. In addition, the small sample volume used in the process ensures significant time and cost savings. Therefore, HME processing on a laboratory scale is a powerful tool for rapid product screening and analysis. However, the scale-up of these laboratory-scale processes is essential during product development. (98,109-111). The scale-up of batch processes is one of the most critical functions in the pharmaceutical industries. Scale-up issues have been responsible for numerous delays in the introduction of drug products onto the market, thereby costing pharmaceutical industries millions of dollars in revenue. Because the HME is a continuous process, the scale-up is a lot easier to achieve than the scale-up of a batch process is, since increasing the batch size only requires a longer run time using the same equipment and process parameters. Transferring the HME process from a small to larger extruder requires characterization of the HME process to verify that the transferred process has not been altered. The HME variables that are used to confirm the precise replication of the process parameters are listed as below:

1. Melt temperature.

2. Melt viscosity.

3. Mechanical strength of the die.

4. Distribution of melt within the device.

5. Geometry of the dies.

The three different parameters used to conduct scale-up processes are described by Dreiblatt (112). The first scale-up parameter is the batch size, and the only variable applied in this type of scale-up is the extruder operation time while the other parameters remain unchanged. Therefore, the production rate increases with the increase in batch size. The second scale-up parameter is the feed rate, which may or may not have an effect on the final product. However, increasing or decreasing the feed rate changes the residence time of the material in the barrel, resulting in changes in the extrusion process. Any changes in the average residence time could have a significant impact on the resulting product performance. The third parameter is the extruder diameter. Based on the differences between two extruders, transferring from a small to large extruder may change the extrusion process. Generally, the basic geometry of screw elements should match or be similar between different-sized extruders when scaling up. In addition, it is important to identify the process limitations of the HME such as volume, power, or heat transfer (112).

\section{PROCESS OPTIMIZATION USING QBD APPROACHES}

The US Food and Drug Administration (FDA) defines the highest quality drug product as one that consistently and reliably delivers the clinical performance and is free of contaminants $(113,114)$. The concept of QbD is an approach promoted by the US FDA, European Medicine Agency (EMA), and other global regulatory agencies, which were established to ensure the better understanding of the pharmaceutical manufacturing process at any phase of the development cycle of pharmaceutical product as well as during the commercial production. In addition, this approach was aimed at encouraging a better understanding of the product 
and process design, process improvement, scale-up, optimization, and control, thereby ensuring an improvement in the process efficiency and product quality. According to the International Conference on Harmonization (ICH) Q8, quality cannot be tested into a product but must be incorporated by design (115). The QbD, which was first introduced to the pharmaceutical industry in 2006 by the ICH Q8 guidance (116), is a comprehensive approach that targets all phases of drug discovery, manufacturer, and delivery with the aim of improving the quality and reducing the cost of medicines for the consumers. In the QbD approach, a Fishbone or Ishikawa diagram is created to structure the process of identifying possible factors that could affect the characteristics of the finished product (Fig. 11). The QbD, which is clearly a superior approach, therefore, replaces the traditional approach of quality by testing (QbT) previously used in the industry. Because the QbT involves extensive testing with no flexibility in the process conditions, batch failures occur constantly for no apparent reasons while in contrast, the $\mathrm{QbD}$ offers operational flexibility as long as product variables and process conditions are maintained within an approved design space (117). The goal of the QbD is to encourage industries to adopt innovative technologies that would increase product quality without raising concerns that a new approach would increase risks in the manufacturing process and delays in production. A good QbD approach includes a systematic evaluation of product attributes as well as an understanding and refining of the formulation and manufacturing process. The main components of the $\mathrm{QbD}$ are illustrated in Fig. 12 (118-122) and an overview of a typical quality risk management process is provided in Fig. 13 (123).

One of the most important elements of the QbD approach is the process design space, which is defined by the ICQ 8 as "the multidimensional combination and interaction of input variables including material attributes and process parameters that have been demonstrated to provide assurance of quality." Working within the design space is not considered a change in the approved range for processing parameters and input variables while movement out of the design space is and would normally require the initiation of a regulatory post-approval change process. The design space is proposed by the applicant and is subject to regulatory assessment and approval (115).

Another important component of QbD is the PAT, which the US FDA defines as a mechanism to design, analyze, and control pharmaceutical manufacturing processes via the measurement of critical process parameters that affect critical quality attributes.

A desired goal of the PAT framework is to design and develop well-understood processes that will consistently give a predefined quality at the end of the manufacturing process (124). The FDA guidelines divide the PAT framework into the four steps to design and optimize drug formulations and manufacturing processes, enumerated below:

1. Identify and measure critical material and process attributes relating to the product quality.

2. Design a process measurement system that allows realtime or near-real monitoring of all critical attributes. There are different measurements available to monitor the PAT such as

- At-line: measurement where the sample is removed, isolated, and analyzed in close proximity to the process stream;

- In-line: measurement where the sample is not removed from the process stream and can be invasive or non-invasive;

- On-line: measurement where the sample is diverted from the manufacturing process and may be returned to the process stream; and

- Off-line: measurement disconnected in a timely and local manner from the manufacturing process (124).

3. Design process controls that provide adjustments to ensure control of all critical attributes.

4. Develop mathematical relationships between product quality attributes and measurements of critical material and process attributes.

The implementation of PAT is associated with numerous benefits such as lower production cycle times, improved manufacturing efficiency, reduced product rejection, and increased production operating time. The main components of this knowledge-based approach are a better understanding of the product manufacturing process, data analysis, process analytical tools, process monitoring, and continuous feedback during the manufacturing process. Several research articles have been published about the application of PAT in HME processes. NIR and Raman spectroscopy are the most common techniques used as PAT tools in the pharmaceutical industry (125-129), and NIR has been applied in monitoring the API content of extruded films (130-132).

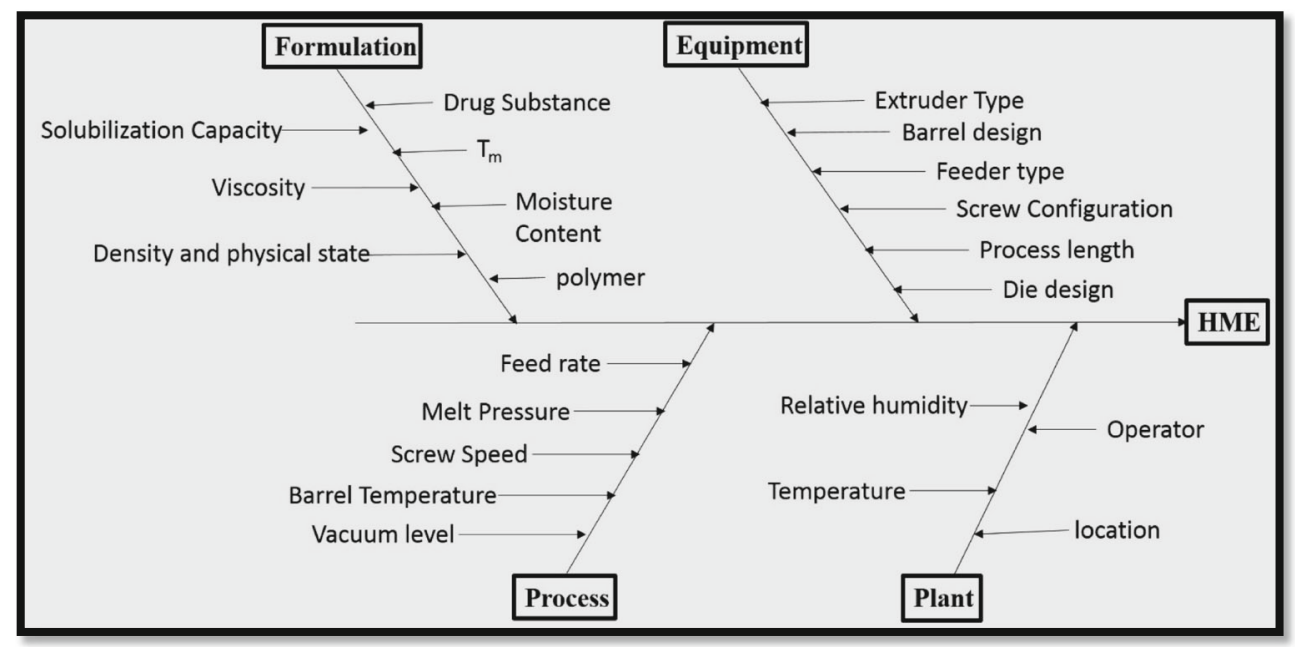

Fig. 11. Ishikawa diagram 


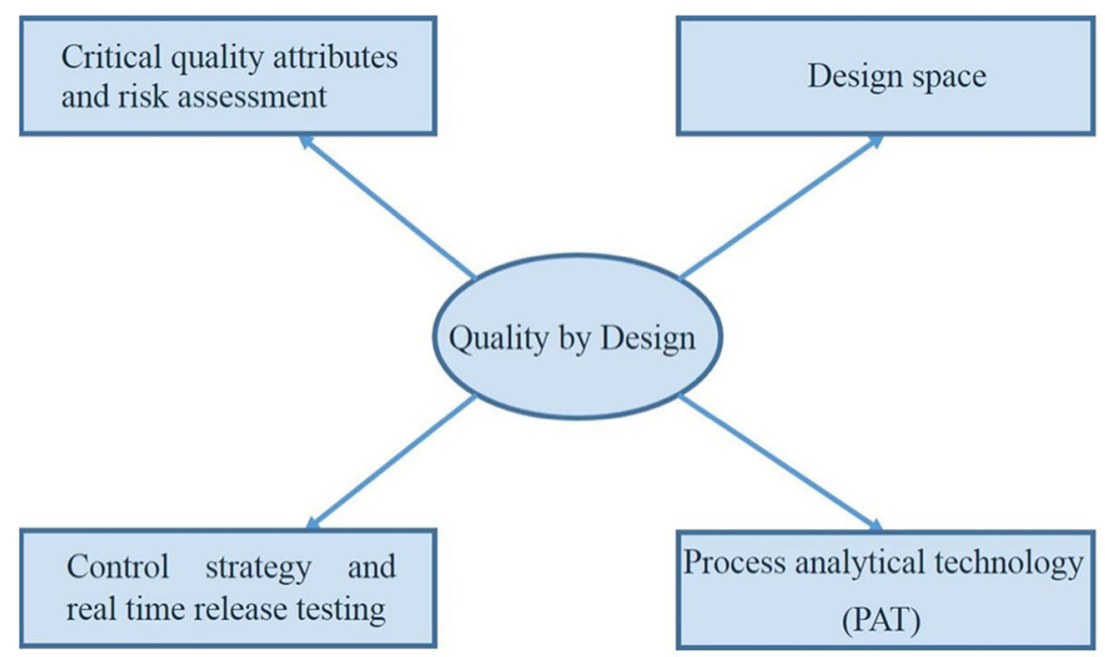

Fig. 12. Components of quality by design approach

Saerens et al. (133) studied the suitability of using Raman spectroscopy as a PAT tool for the in-line polymer-drug quantification and solid-state characterization of a pharmaceutical HME process. MPT and Eudragit ${ }^{\circledR}$ RL PO were the model drug and carrier, respectively, used to prepare extrudates and then the API quantification was performed. The analyses of the Raman spectra from the extrusion processes revealed two

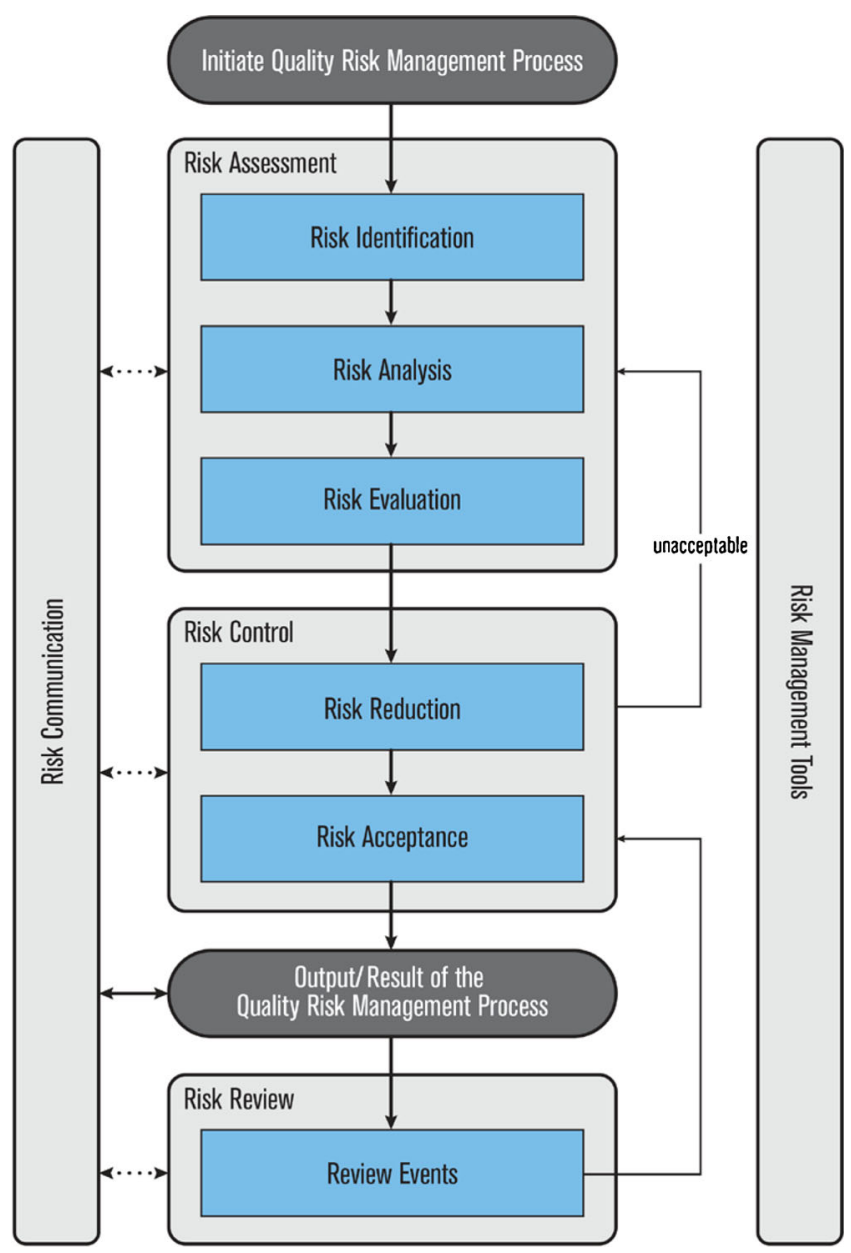

Fig. 13. Overview of a typical quality risk management process (123) main observations. Firstly, the MPT Raman peaks in the solid solution were broadened compared to the corresponding solid dispersion peaks, indicating the presence of amorphous MPT. Secondly, peak shifts were observed in the spectra of the solid dispersion and solid solution compared to the spectra of the physical mixtures, which suggests an interaction between the Eudragit ${ }^{\circledR}$ RS PO and MPT (most likely hydrogen bond interactions). Furthermore, these shifts were larger in the spectra of the solid solution than they were in the other spectra. Therefore, the authors concluded that Raman spectroscopy is a potentially suitable PAT tool for the in-line determination of the API concentration and polymer-drug solid-state during pharmaceutical HME processes (133).

Recently, Saerens et al. (134) further used NIR instead of Raman spectroscopy for the in-line measurement of the API content and evaluation of polymer-API solid-state behavior and molecular interactions during HME processes (134). The in-line NIR spectroscopic monitoring setup is illustrated in Fig. 14. In this study, the authors also used MPT as a model drug and Kollidon ${ }^{\circledR}$ SR as a carrier. The NIR spectra indicated the presence of amorphous MPT and hydrogen bonds between the drug and polymer in the extrudates. The DSC and ATR-FTIR were used to confirm the NIR observations, and based on these results, this research group concluded that NIR spectroscopy is also a potentially suitable PAT tool for the in-line determination of API concentrations and polymerdrug solid-state behavior monitoring during pharmaceutical HME processes.

Krier et al. (135) used PAT tools to control the coextrusion implant manufacturing process. The authors used two different laser measurements namely NIR and Raman spectroscopy and four critical quality attributes including the implant diameter, the quantity of the API, the homogeneous distribution of the API, and the membrane thickness. Furthermore, this study was the first report of the measurement of an API in implants during the pharmaceutical HME process, using NIR and Raman spectroscopy as PAT tools, and Fig. 15 shows the extruder setup with the NIR and Raman probes (135).

Kelly et al. (136) also used NIR spectroscopy as a PAT tool to monitor IBU-nicotinamide co-crystal formation during solvent free continuous co-crystallization using a co-rotating 


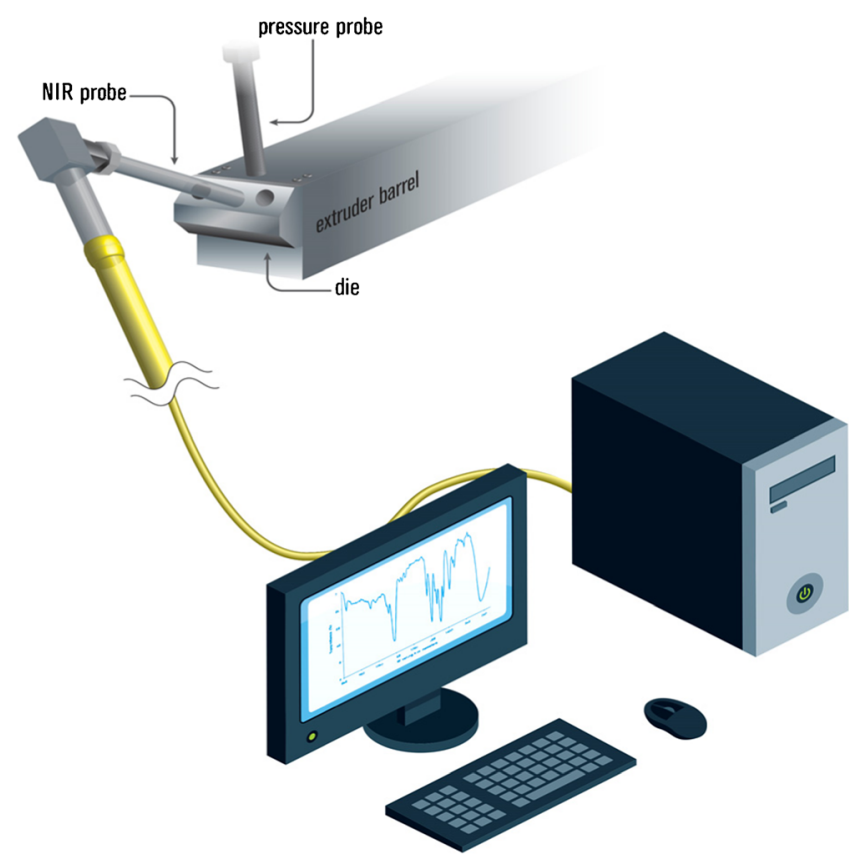

Fig. 14. In-line near-infrared (NIR) spectroscopic monitoring setup
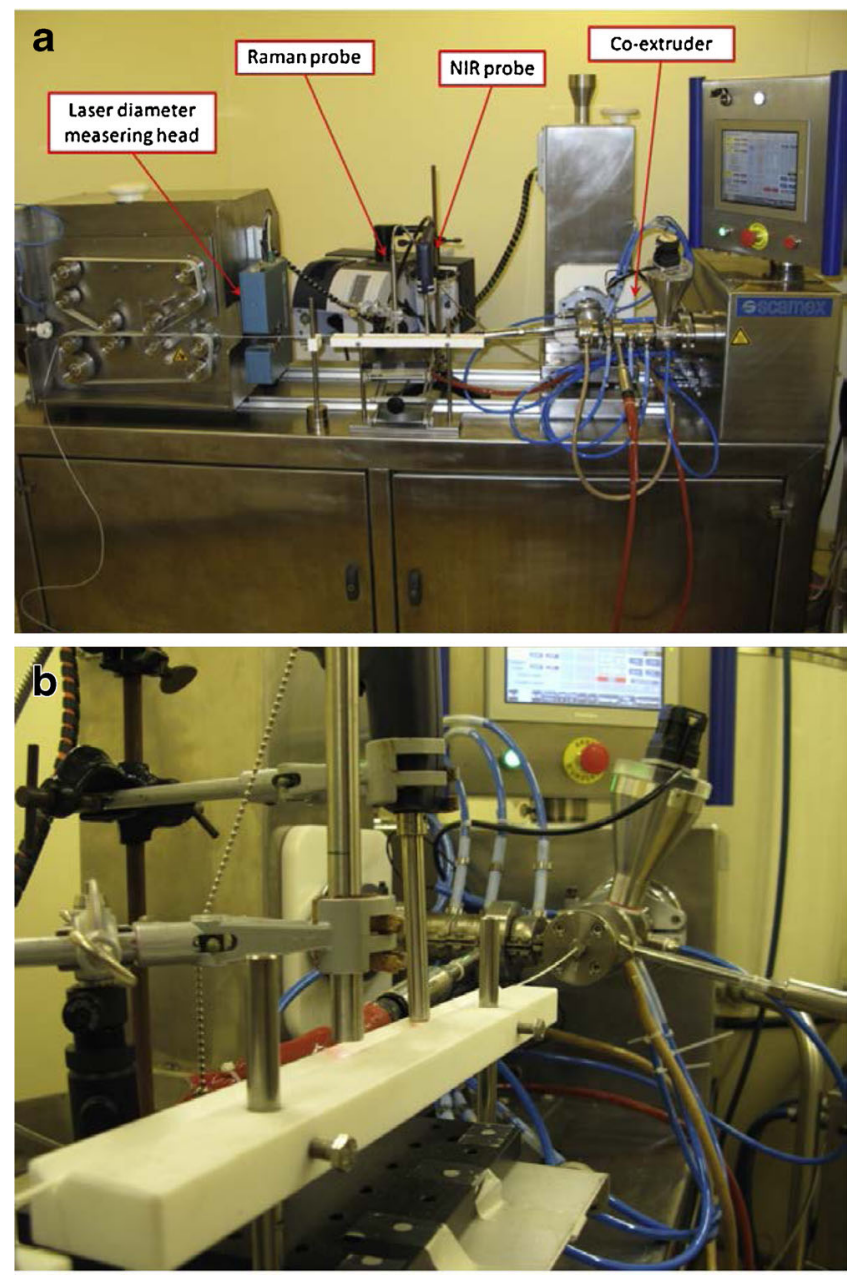

Fig. 15. a Co-extruder equipment. b Interfacing of extruder by nearinfrared (NIR) and Raman fiber optic probe (135)
TSE. The raw materials were gravimetrically fed into the heated extruder, and the high-temperature NIR probe was used in the extruder die to assess the co-crystal content. Then, it was compared to the off-line XRD measurements. The temperature and mixing intensity were considered the process variables, and their effects on the extent of co-crystal were investigated. The NIR spectroscopy provided information on the formation of the IBU-nicotinamide co-crystals by showing the new peaks or absence of peaks in the $4800-5200 \mathrm{~cm}^{-1}$ wavenumber regions. The powder (P) XRD measurements of the co-crystal purity were used as a calibration tool for the NIR measurements using a partial least squares regression. The authors found a correlation between the predicted and measured co-crystal purity of all the extruded samples. These results highlighted the potential of NIR spectroscopy for use as a real-time technique to monitor co-crystal formation during the TSE extrusion process (136).

Wahl et al. (125) studied the PAT strategy in the production of paracetamol embedded in a calcium stearate matrix via HME. In-line NIR spectroscopy was used as a PAT tool, to monitor the extrusion process, and a probe was located in the section between the extrusion screws and the die using a novel design for the die channel. The NIR probe measured the API content of the melt and provided a better understanding of the factors affecting content uniformity. Three different parameters including the API concentrations, screw speeds, and screw designs were monitored in this experiment (125). The highlighted studies have clearly demonstrated the feasibility and advantages of using PAT strategies including the in-line NIR measurements and Raman spectroscopy in pharmaceutical HME processes. These techniques have been proven as powerful tools for application in process development for the characterization of mixing status, as well as for monitoring and additional control strategies.

\section{CONCLUSION AND FUTURE PERSPECTIVES}

Over the past few decades, HME technology has emerged as an attractive novel process for manufacturing drug delivery systems. HME has been well explored and documented as a continuous, solvent-free, robust, quick, and costeffective manufacturing process for the production of a wide variety of pharmaceutical dosage forms including oral, topical films, implants, and ophthalmic inserts. The SSE and TSE are gradually replacing traditional batch processes because of the consistent and reproducible nature of the continuous extrusion. There is growing interest in HME technology because it is suitable for both high and very potent low-dose compounds, and the equipment is widely available. However, despite the numerous obvious advantages of this technique, HME is not yet a common manufacturing tool for drug delivery systems. Currently, the numbers of drug products on the market manufactured using HME are limited because a few drawbacks have impeded its widespread application in the pharmaceutical industry. For instance, compared to other pharmaceutical techniques, HME requires a higher energy input mainly associated with the shear forces and temperatures used, and a number of thermolabile compounds have had to be excluded from this process due to high processing temperatures. However, changes in the design of the equipment (screw assemblies and extruder die) as well as the 
addition of plasticizers may contribute to reduce the processing temperatures and residence time and, thereby, avoid the thermal degradation of APIs during processing.

The FDA has recognized the unique adaptability of the HME technology to QbD and PAT strategies. The QbD approach involves the use of knowledge management and the formal design of experiments to generate and refine the design space throughout the life cycle of the product. Therefore, process engineers are currently working closely with pharmaceutical scientists and executives to understand and refine the formulation and manufacturing process by identifying quality risk management principles, to establish appropriate control strategies.

In conclusion, HME as a continuous pharmaceutical manufacturing process has immense adaptability and potential to replace the traditional batch process. Furthermore, with the incorporation and assistance of QbD and PAT approaches, the HME process can easily facilitate the scale-up from the laboratory to the commercial scale. This attractive feature of scalability exhibited by HME is expected to increase the demand for extrusion processes in pharmaceutical manufacturing in the future.

\section{REFERENCES}

1. El-Egakey MA, Soliva M, Speiser P. Hot extruded dosage forms. Technology and dissolution kinetics of polymeric matrices. Pharm Acta Helv. 1971;46(1):31-52.

2. Dreiblatt A. Process design. In: Ghebre-Sellassie I, Martin C, editors. Pharmaceutical extrusion technology, vol. 133. New York: Marcel Dekker, Inc; 2003. p. 153-69.

3. McGinity JW, Zhang F, Koleng J, Repka M. Hot-melt extrusion as a pharmaceutical process. Am Pharm Rev. 2001;4:25-37.

4. Breitenbach J. Melt extrusion: from process to drug delivery technology. Eur J Pharm Biopharm. 2002;54(2):107-17.

5. Shah S, Repka MA. Melt extrusion in drug delivery: three decades of progress. In: Repka MA, Langley N, DiNunzio J, editors. Melt extrusion. New York: Springer; 2013. p. 3-46.

6. Crowley MM, Zhang F, Repka MA, Thumma S, Upadhye SB, Battu SK, et al. Pharmaceutical applications of hot-melt extrusion: part I. Drug Dev Ind Pharm. 2007;33(9):909-26.

7. Repka MA, Battu SK, Upadhye SB, Thumma S, Crowley MM, Zhang F, et al. Pharmaceutical applications of hot-melt extrusion: part II. Drug Dev Ind Pharm. 2007;33(10):1043-57.

8. Patil H, Kulkarni V, Majumdar S, Repka MA. Continuous manufacturing of solid lipid nanoparticles by hot melt extrusion. Int J Pharm. 2014;471(1-2):153-6.

9. Repka MA, Majumdar S, Kumar Battu S, Srirangam R, Upadhye SB. Applications of hot-melt extrusion for drug delivery. Expert Opin Drug Deliv. 2008;5(12):1357-76.

10. Repka MA, Shah S, Lu J, Maddineni S, Morott J, Patwardhan $\mathrm{K}$, et al. Melt extrusion: process to product. Expert Opin Drug Deliv. 2012;9(1):105-25.

11. Shah S, Maddineni S, Lu J, Repka MA. Melt extrusion with poorly soluble drugs. Int J Pharm. 2013;453(1):233-52.

12. Patil H, Tiwari RV, Upadhye SB, Vladyka RS, Repka MA. Formulation and development of $\mathrm{pH}$-independent/dependent sustained release matrix tablets of ondansetron $\mathrm{HCl}$ by a continuous twin-screw melt granulation process. Int J Pharm. 2015. doi:10.1016/j.ijpharm.2015.04.009.

13. Kleinebudde P, Lindner H. Experiments with an instrumented twin-screw extruder using a single-step granulation/extrusion process. Int J Pharm. 1993;94(1):49-58.

14. Cheremisinoff NP. Guidebook to extrusion technology. Englewood Cliffs, NJ: Prentice-Hall; 1993. p. 23-38.

15. Maniruzzaman M, Boateng JS, Snowden MJ, Douroumis D. A review of hot-melt extrusion: process technology to pharmaceutical products. ISRN Pharm. 2012. doi:10.5402/2012/436763.
16. Steiner R. Extruder design. In: Ghebre-Sellassie I, Martin C, editors. Pharmaceutical extrusion technology, vol. 133. New York: Marcel Dekker, Inc; 2003. p. 19-38.

17. Luker K. Single-screw extrusion: principle. In: Douroumis D, editor. Hot-melt extrusion: pharmaceutical application. 1st ed. UK: John Wiley \& Sons, Ltd; 2012. p. 1-21.

18. Stevens M, Covas J. Extrusion, principles and operation. 2nd ed. London: Chapman \& Hall; 1995. p. 270-95.

19. Mollan M. Historical overview. In: Ghebre-Sellassie I, Martin C, editors. Pharmaceutical extrusion technology, vol. 133. New York: Marcel Dekker, Inc; 2003. p. 1-18.

20. Thiele W. Twin-screw extrusion and screw design. In: GhebreSellassie I, Martin C, editors. Pharmaceutical extrusion technology, vol. 133. New York: Marcel Dekker, Inc; 2003. p. 69-98.

21. Repka MA, McGinity JW, Zhang F, Koleng JJ. Hot-melt extrusion technology. In: Swarbrick J, Boylan J, editors. Encyclopedia of pharmaceutical technology. 2nd ed. New York: Marcel Dekker; 2002. p. 203-66.

22. Wang Y. Compounding in co-rotating twin-screw extruders. Shrewsbury UK: Smithers RAPRA; Report 116, 2000. p. 3.

23. Loukus JE, Halonen A, Gupta M. Elongational flow in multiple screw extruders. ANTEC-Conference Proceeding. 2004;1:133137.

24. Luker K. Single-screw extrusion and screw design. In: GhebreSellassie I, Martin C, editors. Pharmaceutical extrusion technology, vol. 133. New York: Marcel Dekker, Inc; 2003. p. 39-68.

25. Chokshi R, Zia H. Hot-melt extrusion technique: a review. Iran J Pharm Res. 2010;3:3-16.

26. Nakamichi K, Yasuura H, Kukui H, Oka M, Izumi S, Andou T, et al. New preparation method of solid dispersion by twin screw extruder. Pharm Technol Jpn. 1996;12:715-29.

27. Douroumis D. Taste masking using hot-melt extrusion. In: Douroumis D, editor. Hot-melt extrusion: pharmaceutical application. 1st ed. UK: John Wiley \& Sons, Ltd; 2012. p. 201-21.

28. Gogos CG, Liu H, Wang P. Laminar dispersive and distributive mixing with dissolution and applications to hot-melt extrusion. In: Douroumis D, editor. Hot-melt extrusion: pharmaceutical applications. 1st ed. UK: John Wiley \& Sons, Ltd; 2012. p. 261-84.

29. Dreiblatt A. Technological considerations related to scale-up of hot-melt extrusion processes. In: Douroumis D, editor. Hot-melt extrusion: pharmaceutical application. 1st ed. UK: John Wiley \& Sons, Ltd; 2012. p. 285-300.

30. Perdikoulias J, Dobbie T. Die design. In: Ghebre-Sellassie I, Martin C, editors. Pharmaceutical extrusion technology. New York: Marcel Dekker, Inc; 2003. p. 99-109.

31. Verreck G. The influence of plasticizers in hot-melt extrusion. In: Douroumis D, editor. Hot-melt extrusion: pharmaceutical application. 1st ed. UK: John Wiley \& Sons, Ltd; 2012. p. 93-112.

32. Repka MA, Shah S, Lu J, Maddineni S, Morott J, Patwardhan $\mathrm{K}$, et al. Melt extrusion: process to product. Expert Opin Drug Deliv. 2012;9(1):105-25.

33. Miyagawa Y, Okabe T, Yamaguchi Y, Miyajima M, Sato H, Sunada H. Controlled-release of diclofenac sodium from wax matrix granule. Int J Pharm. 1996;138(2):215-24.

34. Tantishaiyakul V, Kaewnopparat N, Ingkatawornwong S. Properties of solid dispersions of piroxicam in polyvinylpyrrolidone. Int J Pharm. 1999;181(2):143-51.

35. Zingone G, Moneghini M, Rupena P, Vojnovic D. Characterization and dissolution study of solid dispersions of theophylline and indomethacin with PVP/VA copolymers. STP Pharm Sci. 1992;2(2):186-92.

36. Follonier N, Doelker E, Cole ET. Various ways of modulating the release of diltiazem hydrochloride from hot-melt extruded sustained release pellets prepared using polymeric materials. J Control Release. 1995;36(72):243-50.

37. Perissutti B, Newton JM, Podczeck F, Rubessa F. Preparation of extruded carbamazepine and PEG 4000 as a potential rapid release dosage form. Eur J Pharm Biopharm. 2002;53(1):125-32.

38. Yano K, Kajiyama A, Hamada M, Yamamoto K. Constitution of colloidal particles formed from a solid dispersion system. Chem Pharm Bull. 1997;45(8):1339-44.

39. Abd A, El-Bary A, Geneidi AS, Amin SY, Elainan AA. Preparation and pharmacokinetic evaluation of carbamazepine 
controlled release solid dispersion granules. J Drug Res Egypt. 1998;22:15-31.

40. Li L, AbuBaker O, Shao ZJ. Characterization of poly(ethylene oxide) as a drug carrier in hot-melt extrusion. Drug Dev Ind Pharm. 2006;32(8):991-1002.

41. Repka MA, Gerding TG, Repka SL, McGinity JW. Influence of plasticizers and drugs on the physical-mechanical properties of hydroxypropylcellulose films prepared by hot melt extrusion. Drug Dev Ind Pharm. 1999;25(5):625-33.

42. Ahmed HA, Alfredson TV, Birudaraj K, Brandl MT, Phuapradit W, Shah NH, et al. Pharmaceutical composition and process. U.S. Patent 7,795,237, September 14, 2010.

43. Repka MA, McGinity JW. Influence of chlorpheniramine maleate on topical hydroxypropylcellulose films produced by hotmelt extrusion. Pharm Dev Technol. 2001;6(72):297-304.

44. Quinten T, Andrews GP, De Beer T, Saerens L, Bouquet W, Jones DS, et al. Preparation and evaluation of sustained-release matrix tablets based on metoprolol and an acrylic carrier using injection moulding. AAPS PharmSciTech. 2012;13(4):1197-211.

45. Hancock BC, Zografi G. Characteristics and significance of the amorphous state in pharmaceutical systems. J Pharm Sci. 1997;86(1):1-12.

46. Follonier N, Doelker E, Cole ET. Evaluation of hot-melt extrusion as a new technique for the production of polymer-based pellets for sustained release capsules containing high loadings of freely soluble drugs. Drug Dev Ind Pharm. 1994;20(8):1323-39.

47. Cuff G, Raouf F. A preliminary evaluation of injection molding as a technology to produce tablets. Pharm Technol. 1998;22(6):96-106.

48. Aitken-Nichol C, Zhang F, McGinity JW. Hot melt extrusion of acrylic films. Pharm Res. 1996;13(5):804-8.

49. Mehuys E, Remon JP, Vervaet C. Production of enteric capsules by means of hot-melt extrusion. Eur J Pharm Sci. 2005;24(23):207-12.

50. Repka MA, McGinity JW. Physical-mechanical, moisture absorption and bioadhesive properties of hydroxypropylcellulose hot-melt extruded films. Biomaterials. 2000;21(14):1509-17.

51. Ghebremeskel AN, Vemavarapu C, Lodaya M. Use of surfactants as plasticizers in preparing solid dispersions of poorly soluble API: stability testing of selected solid dispersions. Pharm Res. 2006;23(8):1928-36.

52. De Brabander C, Van Den Mooter G, Vervaet C, Remon JP. Characterization of ibuprofen as a nontraditional plasticizer of ethyl cellulose. J Pharm Sci. 2002;91(7):1678-85.

53. Verreck G, Six K, Van den Mooter G, Baert L, Peeters J, Brewster ME. Characterization of solid dispersions of itraconazole and hydroxypropylmethylcellulose prepared by melt extrusion-part I. Int J Pharm. 2003;251(1-2):165-74.

54. Six K, Berghmans H, Leuner C, Dressman J, Van Werde K, Mullens $\mathrm{J}$, et al. Characterization of solid dispersions of itraconazole and hydroxypropylmethylcellulose prepared by melt extrusion. Part II. Pharm Res. 2003;20(7):1047-54.

55. Lakshman JP, Cao Y, Kowalski J, Serajuddin AT. Application of melt extrusion in the development of a physically and chemically stable high-energy amorphous solid dispersion of a poorly water-soluble drug. Mol Pharm. 2008;5(6):994-1002.

56. Kazarian S. Polymer processing with supercritical fluids. Polym Sci Ser C. 2000;42(1):78-101.

57. Kiran E. Polymer formation, modifications and processing in or with supercritical fluids, Supercritical fluids. New York: Springer; 1994. p. 541-88.

58. Chiou J, Barlow JW, Paul DR. Plasticization of glassy polymers by CO2. J Appl Polym Sci. 1985;30(6):2633-42.

59. Verreck G, Decorte A, Li H, Tomasko D, Arien A, Peeters J, et al. The effect of pressurized carbon dioxide as a plasticizer and foaming agent on the hot melt extrusion process and extrudate properties of pharmaceutical polymers. J Supercrit Fluids. 2006;38:383-91.

60. DiNunzio JC, Zhang F, Martin C, McGinity JW. Melt extrusion. In: Robet III OW, Watts AB, Miller DA, editors. Formulating poorly water soluble drugs. New York: Springer; 2012. p. 31162.

61. Leuner C, Dressman J. Improving drug solubility for oral delivery using solid dispersions. Eur J Pharm Biopharm. 2000;50(1):47-60.
62. Breitenbach J, Magerlein M. Melt extruded molecular dispersions. In: Ghebre-Sellassie I, Martin C, editors. Pharmaceutical extrusion technology, vol. 133. New York: Marcel Dekker Inc; 2003. p. $245-60$.

63. Serajuddin AT. Solid dispersion of poorly water-soluble drugs: early promises, subsequent problems, and recent breakthroughs. J Pharm Sci. 1999;88(10):1058-66.

64. Hulsmann S, Backensfeld T, Keitel S, Bodmeier R. Melt extrusion-an alternative method for enhancing the dissolution rate of 17beta-estradiol hemihydrate. Eur J Pharm Biopharm. 2000;49(3):237-42.

65. Nakamichi K, Nakano T, Yasuura H, Izumi S, Kawashima Y. The role of the kneading paddle and the effects of screw revolution speed and water content on the preparation of solid dispersions using a twin-screw extruder. Int $\mathrm{J}$ Pharm. 2002;241(2):203-11.

66. He H, Yang R, Tang X. In vitro and in vivo evaluation of fenofibrate solid dispersion prepared by hot-melt extrusion. Drug Dev Ind Pharm. 2010;36(6):681-7.

67. Sathigari SK, Radhakrishnan VK, Davis VA, Parsons DL, Babu RJ. Amorphous-state characterization of efavirenz-polymer hotmelt extrusion systems for dissolution enhancement. J Pharm Sci. 2012;101(9):3456-64.

68. Wang W, Kang Q, Liu N, Zhang Q, Zhang Y, Li H, et al. Enhanced dissolution rate and oral bioavailability of Ginkgo biloba extract by preparing solid dispersion via hot-melt extrusion. Fitoterapia. 2014. doi:10.1016/j.fitote.2014.10.004.

69. Alshahrani SM, Lu W, Park JB, Morott JT, Alsulays BB, Majumdar S, et al. Stability-enhanced hot-melt extruded amorphous solid dispersions via combinations of Soluplus ${ }^{\circledR}$ and HPMCAS-HF. AAPS PharmSciTech. 2015. doi:10.1208/s12249014-0269-6.

70. Mehuys E, Vervaet C, Remon JP. Hot-melt extruded ethylcellulose cylinders containing a HPMC-Gelucire core for sustained drug delivery. J Control Release. 2004;94(2-3):273-80.

71. Yamashita F, Hashida M. Pharmacokinetic considerations for targeted drug delivery. Adv Drug Deliv Rev. 2013;65(1):139-47.

72. Bruce LD, Shah NH, Malick AW, Infeld MH, McGinity JW. Properties of hot-melt extruded tablet formulations for the colonic delivery of 5-aminosalicylic acid. Eur J Pharm Biopharm. 2005;59(1):85-97.

73. Miller DA, DiNunzio JC, Yang W, McGinity JW, Williams 3rd RO. Targeted intestinal delivery of supersaturated itraconazole for improved oral absorption. Pharm Res. 2008;25(6):1450-9.

74. Cassidy CM, Tunney MM, Caldwell DL, Andrews GP, Donnelly RF. Development of novel oral formulations prepared via hot melt extrusion for targeted delivery of photosensitizer to the colon. Photochem Photobiol. 2011;87(4):867-76.

75. Remington JP, Troy DB, Beringer P. Remington: the science and practice of pharmacy. 20th ed. Easton: Mack Publishing Company; 2002. p. 1018-20.

76. Gryczke A, Schminke S, Maniruzzaman M, Beck J, Douroumis D. Development and evaluation of orally disintegrating tablets (ODTs) containing Ibuprofen granules prepared by hot melt extrusion. Colloids Surf B: Biointerfaces. 2011;86(2):275-84.

77. Michalk A, Kanikanti VR, Hamann HJ, Kleinebudde P. Controlled release of active as a consequence of the die diameter in solid lipid extrusion. J Control Release. 2008;132(1):35-41.

78. Witzleb R, Kanikanti VR, Hamann HJ, Kleinebudde P. Solid lipid extrusion with small die diameters-electrostatic charging, taste masking and continuous production. Eur J Pharm Biopharm. 2011;77(1):170-7.

79. Breitkreutz J, El-Saleh F, Kiera C, Kleinebudde P, Wiedey W. Pediatric drug formulations of sodium benzoate: II. Coated granules with a lipophilic binder. Eur J Pharm Biopharm. 2003;56(2):255-60.

80. Maniruzzaman M, Boateng JS, Bonnefille M, Aranyos A, Mitchell JC, Douroumis D. Taste masking of paracetamol by hot-melt extrusion: an in vitro and in vivo evaluation. Eur $\mathrm{J}$ Pharm Biopharm. 2012;80(2):433-42.

81. Douroumis D. Practical approaches of taste masking technologies in oral solid forms. Expert Opin Drug Deliv. 2007;4(4):417-26.

82. Douroumis D. Orally disintegrating dosage forms and tastemasking technologies; 2010. Expert Opin Drug Deliv. 2011;8(5):665-75. 
83. Morott JT, Pimparade M, Park JB, Worley CP, Majumdar S, Lian Z, et al. The effects of screw configuration and polymeric carriers on hot-melt extruded taste-masked formulations incorporated into orally disintegrating tablets. J Pharm Sci. 2015;104(1):124-34.

84. Steuernagel CR. Latex emulsions for controlled drug delivery. In: McGinity JW, editor. Aqueous polymeric coatings for pharmaceutical dosage forms, vol. 79. New York, USA: Marcel Dekker; 1997.

85. Barnhart S. Thin film oral dosage forms. In: Rathbone MJ, Hadgraft J, Roberts MS, Lane ME, editors. Modified-release drug delivery technology. New York: Informa Healthcare; 2008. p. 209-16.

86. Repka MA, Gutta K, Prodduturi S, Munjal M, Stodghill SP. Characterization of cellulosic hot-melt extruded films containing lidocaine. Eur J Pharm Biopharm. 2005;59(1):189-96.

87. Mididoddi PK, Repka MA. Characterization of hot-melt extruded drug delivery systems for onychomycosis. Eur J Pharm Biopharm. 2007;66(1):95-105.

88. Low AQ, Parmentier J, Khong YM, Chai CC, Tun TY, Berania $\mathrm{JE}$, et al. Effect of type and ratio of solubilising polymer on characteristics of hot-melt extruded orodispersible films. Int $\mathbf{J}$ Pharm. 2013;455(1-2):138-47.

89. Palem CR, Kumar Battu S, Maddineni S, Gannu R, Repka MA, Yamsani MR. Oral transmucosal delivery of domperidone from immediate release films produced via hot-melt extrusion technology. Pharm Dev Technol. 2013;18(1):186-95.

90. Chen M, Lu J, Deng W, Singh A, Mohammed NN, Repka MA, et al. Influence of processing parameters and formulation factors on the bioadhesive, temperature stability and drug release properties of hot-melt extruded films containing miconazole. AAPS PharmSciTech. 2014;15(3):522-9.

91. Rothen-Weinhold A, Oudry N, Schwach-Abdellaoui K, Frutiger-Hughes S, Hughes GJ, Jeannerat D, et al. Formation of peptide impurities in polyester matrices during implant manufacturing. Eur J Pharm Biopharm. 2000;49(3):253-7.

92. Ghalanbor Z, Korber M, Bodmeier R. Improved lysozyme stability and release properties of poly(lactide-co-glycolide) implants prepared by hot-melt extrusion. Pharm Res. 2010;27(2):371-9.

93. Ghalanbor Z, Korber M, Bodmeier R. Protein release from poly(lactide-co-glycolide) implants prepared by hot-melt extrusion: thioester formation as a reason for incomplete release. Int J Pharm. 2012;438(1-2):302-6.

94. Li D, Guo G, Fan R, Liang J, Deng X, Luo F, et al. PLA/F68/ dexamethasone implants prepared by hot-melt extrusion for controlled release of anti-inflammatory drug to implantable medical devices: I. Preparation, characterization and hydrolytic degradation study. Int J Pharm. 2013;441(1-2):365-72.

95. Stankovic M, Tomar J, Hiemstra C, Steendam R, Frijlink HW, Hinrichs WL. Tailored protein release from biodegradable poly(epsilon-caprolactone-PEG)-b-poly(epsilon-caprolactone) multiblock-copolymer implants. Eur J Pharm Biopharm. 2014;87(2):329-37.

96. Verhoeven E, De Beer TR, Van den Mooter G, Remon JP, Vervaet C. Influence of formulation and process parameters on the release characteristics of ethylcellulose sustainedrelease mini-matrices produced by hot-melt extrusion. Eur J Pharm Biopharm. 2008;69(1):312-9.

97. Ozguney I, Shuwisitkul D, Bodmeier R. Development and characterization of extended release Kollidon SR mini-matrices prepared by hot-melt extrusion. Eur J Pharm Biopharm. 2009;73(1):140-5.

98. Almeida A, Saerens L, De Beer T, Remon JP, Vervaet C. Upscaling and in-line process monitoring via spectroscopic techniques of ethylene vinyl acetate hot-melt extruded formulations. Int J Pharm. 2012;439(1-2):223-9.

99. Patil H, Feng X, Ye X, Majumdar S, Repka MA. Continuous production of fenofibrate solid lipid nanoparticles by hot-melt extrusion technology: a systematic study based on a quality by design approach. AAPS J. 2015;17(1):194-205.

100. Baumgartner R, Eitzlmayr A, Matsko N, Tetyczka C, Khinast J, Roblegg E. Nano-extrusion: a promising tool for continuous manufacturing of solid nano-formulations. Int J Pharm. 2014;477(1-2):1-11.
101. Singh BN, Kim KH. Floating drug delivery systems: an approach to oral controlled drug delivery via gastric retention. J Control Release. 2000;63(3):235-59.

102. Fukuda M, Peppas NA, McGinity JW. Floating hot-melt extruded tablets for gastroretentive controlled drug release system. J Control Release. 2006;115(2):121-9.

103. Van Melkebeke B, Vervaet C, Remon JP. Validation of a continuous granulation process using a twin-screw extruder. Int $\mathbf{J}$ Pharm. 2008;356(1-2):224-30.

104. Gamlen M, Eardley C. Continuous extrusion using a raker perkins MP50 (multipurpose) extruder. Drug Dev Ind Pharm. 1986;12(11-13):1701-13.

105. Lindberg N-O, Tufvesson C, Holm P, Olbjer L. Extrusion of an effervescent granulation with a twin screw extruder, Baker Perkins MPF $50 \mathrm{D}$. Influence on intragranular porosity and liquid saturation. Drug Dev Ind Pharm. 1988;14(13):1791-8.

106. Ghebre-Sellassie I, Mollan MJ, Pathak N, Lodaya M, Fessehaie M. Continuous production of pharmaceutical granulation. US Patent 6,499,984 B1, December 31, 2002

107. Keleb EI, Vermeire A, Vervaet C, Remon JP. Continuous twin screw extrusion for the wet granulation of lactose. Int J Pharm. 2002;239(1-2):69-80.

108. Mu B, Thompson MR. Examining the mechanics of granulation with a hot melt binder in a twin-screw extruder. Chem Eng Sci. 2012;81:46-56.

109. Potente H. Existing scale-up rules for single-screw plasticating extruders. Int Polym Process. 1991;6(4):267-78.

110. Rauwendaal CH. Polymer extrusion. München, Germany: Hanser publishers; 1986. p. 20-5.

111. Guns S, Mathot V, Martens JA, Van den Mooter G. Upscaling of the hot-melt extrusion process: comparison between laboratory scale and pilot scale production of solid dispersions with miconazole and Kollicoat IR. Eur J Pharm Biopharm. 2012;81(3):674-82.

112. Dreiblatt A. Technological considerations related to scale-up of hot-melt extrusion processes. In: Douroumis D, editor. Hot-melt extrusion: pharmaceutical application. 1st ed. Ltd, UK: John Wiley \& Sons; 2012. p. 285-300.

113. Gupta A, Khan MA. Hot-melt extrusion: an FDA perspective on product and process understanding. In: Douroumis D, editor. Hot-melt extrusion: pharmaceutical application. 1st ed. UK: John Wiley \& Sons, Ltd; 2012. p. 323-31.

114. Woodcock J. The concept of pharmaceutical quality. Am Pharm Rev. 2004;7(6):10-5.

115. ICH Q8(R2). Pharmaceutical development. ICH Harmonised Tripartite Guideline. (2009). http://www.ich.org/products/guidelines/quality/quality-single/article/pharmaceuticaldevelopment.html. Accessed 10 April 2015.

116. ICH topic Q3C (R5) impurities: residual solvents. International Conference on Harmonization. 2009. http://www.ich.org/ fileadmin/Public_Web_Site/ICH_Products/Guidelines/Quality/ Q3C/Step4/Q3C_R5_Step4.pdf. Accessed 10 April 2015.

117. Kayrak-Talay D, Dale S, Wassgren C, Litster J. Quality by design for wet granulation in pharmaceutical processing: assessing models for a priori design and scaling. Powder Technol. 2013;240:7-18.

118. Aksu B, De Beer T, Folestad S, Ketolainen J, Lindén H, Lopes $\mathrm{JA}$, et al. Strategic funding priorities in the pharmaceutical sciences allied to quality by design (QbD) and process analytical technology (PAT). Eur J Pharm Sci. 2012;47(2):402-5.

119. Kasper JC, Winter G, Friess W. Recent advances and further challenges in lyophilization. Eur J Pharm Biopharm. 2013;85(2):162-9.

120. Tomba E, Facco P, Bezzo F, Barolo M. Latent variable modeling to assist the implementation of Quality-by-Design paradigms in pharmaceutical development and manufacturing: a review. Int J Pharm. 2013;457(1):283-97.

121. Schaefer C, Clicq D, Lecomte C, Merschaert A, Norrant E, Fotiadu F. A process analytical technology (PAT) approach to control a new API manufacturing process: development, validation and implementation. Talanta. 2014;120:114-25.

122. Chen Z, Lovett D, Morris J. Process analytical technologies and real time process control a review of some spectroscopic issues and challenges. J Process Control. 2011;21(10):1467-82.

123. ICH Q9. Quality risk management. ICH Harmonised Tripartite Guideline. 2006. http://www.ich.org/products/guidelines/quality/ 
quality-single/article/quality-risk-management.html. Accessed 10 April 2015.

124. Guidance for industry PAT-A framework for innovative pharmaceutical manufacturing and quality assurance. 2004. http:// www.fda.gov/downloads/Drugs/Guidances/ucm070305.pdf. Accessed 10 April 2015.

125. Wahl PR, Treffer D, Mohr S, Roblegg E, Koscher G, Khinast JG. Inline monitoring and a PAT strategy for pharmaceutical hot melt extrusion. Int J Pharm. 2013;455(1):159-68.

126. De Beer T, Burggraeve A, Fonteyne M, Saerens L, Remon JP, Vervaet C. Near infrared and Raman spectroscopy for the inprocess monitoring of pharmaceutical production processes. Int J Pharm. 2011;417(1-2):32-47.

127. Gendrin C, Roggo Y, Collet C. Pharmaceutical applications of vibrational chemical imaging and chemometrics: a review. J Pharm Biomed Anal. 2008;48(3):533-53.

128. Roggo Y, Chalus P, Maurer L, Lema-Martinez C, Edmond A, Jent N. A review of near infrared spectroscopy and chemometrics in pharmaceutical technologies. J Pharm Biomed Anal. 2007:44(3):683-700.

129. Vankeirsbilck T, Vercauteren A, Baeyens W, Van der Weken G, Verpoort F, Vergote G, et al. Applications of Raman spectroscopy in pharmaceutical analysis. TrAC Trends Anal Chem. 2002;21(12):869-77.

130. Coates P, Barnes S, Sibley M, Brown E, Edwards HG, Scowen I. In-process vibrational spectroscopy and ultrasound measurements in polymer melt extrusion. Polymer. 2003;44(19):5937-49.
131. Tumuluri SV, Prodduturi S, Crowley MM, Stodghill SP, McGinity JW, Repka MA, et al. The use of near-infrared spectroscopy for the quantitation of a drug in hot-melt extruded films. Drug Dev Ind Pharm. 2004;30(5):505-11.

132. Barnes S, Brown E, Sibley M, Edwards H, Coates P. Vibrational spectroscopic and ultrasound analysis for the inprocess monitoring of poly (ethylene vinyl acetate) copolymer composition during melt extrusion. Analyst. 2005;130(3):286-92.

133. Saerens L, Dierickx L, Lenain B, Vervaet C, Remon JP, De Beer T. Raman spectroscopy for the in-line polymer-drug quantification and solid state characterization during a pharmaceutical hot-melt extrusion process. Eur J Pharm Biopharm. 2011;77(1):158-63.

134. Saerens L, Dierickx L, Quinten T, Adriaensens P, Carleer $\mathrm{R}$, Vervaet $\mathrm{C}$, et al. In-line NIR spectroscopy for the understanding of polymer-drug interaction during pharmaceutical hot-melt extrusion. Eur J Pharm Biopharm. 2012;81(1):230-7.

135. Krier F, Mantanus J, Sacre PY, Chavez PF, Thiry J, Pestieau A, et al. PAT tools for the control of co-extrusion implants manufacturing process. Int J Pharm. 2013;458(1):15-24.

136. Kelly AL, Gough T, Dhumal RS, Halsey SA, Paradkar A. Monitoring ibuprofen-nicotinamide cocrystal formation during solvent free continuous cocrystallization (SFCC) using near infrared spectroscopy as a PAT tool. Int J Pharm. 2012;426(12):15-20. 